\title{
MAVEN/NGIMS thermospheric neutral wind observations: Interpretation using the M-GITM general circulation model
}

\author{
Kali J. Roeten ${ }^{1}$, Stephen W. Bougher ${ }^{1}$, Mehdi Benna ${ }^{2,3}$, Paul R. Mahaffy ${ }^{2}$, Yuni Lee ${ }^{2}$, Dave \\ Pawlowski $^{4}$, Francisco González-Galindo ${ }^{5}$, Miguel Ángel López-Valverde ${ }^{5}$ \\ ${ }^{1}$ Climate and Space Sciences and Engineering Department, University of Michigan, Ann Arbor, Michigan, USA. \\ ${ }^{2}$ Planetary Environments Laboratory, Code 699, NASA Goddard Space Flight Center, Greenbelt, Maryland, USA. \\ ${ }^{3}$ CRESST, University of Maryland, Baltimore County, Baltimore, Maryland, USA. \\ ${ }^{4}$ Physics \& Astronomy Department, Eastern Michigan University, Ypsilanti, MI, USA. \\ ${ }^{5}$ Instituto de Astrofísica de Andalucía/CSIC, Granada, Spain.
}

\section{Key Points:}

- New thermospheric wind observations at Mars are compared to a global circulation model for the first time.

- Winds during observational campaigns with high average wind speeds and little variability were best replicated in model simulations.

- Data-model disagreements suggest processes other than normal solar forcing may become important and alter the expected circulation pattern.

This is the author manuscript accepted for publication and has undergone full peer review but has not been through the copyediting, typesetting, pagination and proofreading process, which may lead to differences between this version and the Version of Record. Please cite this article as doi: 10.1029/2019JE005957

Corresponding author: K. J. Roeten, kjroeten@umich.edu

This article is protected by copyright. All rights reserved. 


\section{Abstract}

Using a new observational technique, the NGIMS (Neutral Gas and Ion Mass Spectrometer) instrument on the MAVEN (Mars Atmosphere and Volatile Evolution) spacecraft has the unique capability to measure horizontal thermospheric winds. Measured along the orbit track from periapsis $(\sim 150 \mathrm{~km})$ to $\sim 200 \mathrm{~km}$, these are the first in-situ observations of thermospheric winds at Mars. Significantly, this also means that simulated winds from a global circulation model can be compared to in-situ observations from this part of the Martian atmosphere for the first time. In this study, observations from five NGIMS neutral wind campaigns have been compared to simulations from the Mars Global IonosphereThermosphere Model (M-GITM), a ground to exosphere 3-D general circulation model. By comparing NGIMS neutral wind observations to model simulations, the processes driving the winds and their variations in the upper atmosphere are examined. These comparisons show that for certain observational periods, the M-GITM simulated winds can generally replicate the magnitude and/or direction of the NGIMS wind observations, while in others, significant differences occur. In general, wind observations from NGIMS campaigns with large orbit-to-orbit variability are not well replicated by M-GITM, while campaigns with higher observed wind speeds are better captured by the model. Additionally, using these data-model comparisons, the relative role of normal solar forcing and corresponding differential heating in driving thermospheric winds at Mars is found to be variable, likely acting as the primary driver under some conditions and secondary to other physical processes under others.

Plain Language Summary:

The MAVEN (Mars Atmosphere and Volatile Evolution) spacecraft, which is currently in orbit around Mars, has been taking monthly measurements of the speed and direction of the winds in the upper atmosphere of Mars between about 150 to $200 \mathrm{~km}$ above the surface. The observed wind speeds and directions change with time and location, and sometimes fluctuate quickly. These measurements are compared to simulations from a computer model of the Mars atmosphere called M-GITM (Mars Global IonosphereThermosphere Model). This is the first comparison between direct measurements of winds in the upper atmosphere of Mars and simulated winds and is important because it can help to inform us what physical process are acting on the observed winds. Some wind 
measurements have similar wind speeds or directions to those predicted by the M-GITM model, but sometimes, there are large differences between the simulated and measured winds. The disagreements between wind observations and model simulations suggest that processes other than normal solar forcing may become relatively more important during these observations and alter the expected circulation pattern. Understanding the processes that drive the winds in the upper atmosphere of Mars provides key context for understanding how the atmosphere behaves as a whole system.

\section{Background and Motivation}

The thermosphere is a region of the upper atmosphere of Mars where absorption of solar extreme ultraviolet (EUV) radiation heats the atmosphere, causing temperatures to increase with height before approaching isothermal values near the exobase. It extends from the mesopause (the coldest region of the atmosphere, $\sim 100 \mathrm{~km}$ ) to the exobase (the region where the atmosphere begins to transition to a predominantly collisionless environment, $200 \mathrm{~km}$ ) [Bougher et al., 2017a]. The thermosphere is strongly coupled with both the denser atmosphere below and the sparser exosphere above, and as such, regulates how energy and material flow into and out of the middle-lower atmosphere [Bougher et al., 2015a].

Observations from several spacecraft have allowed for improved characterization of the upper atmosphere. This includes densities measured in-situ during the aerobraking campaigns of Mars Global Surveyor (MGS), Mars Odyssey, and Mars Reconnaissance Orbiter (MRO) [e.g. Keating et al., 1998; Tolson et al., 2005; Keating et al., 2007], observations of airglow leading to derived temperatures and densities by the Mariner 6, 7, and 9 missions and Mars Express [e.g. Stewart, 1972; Stewart et al., 1972; Leblanc et al., 2006], and temperatures derived from stellar occultations conducted by Mars Express [e.g. Forget et al., 2009]. Since 2014, the MAVEN mission, which was specifically designed to examine the upper atmosphere of Mars, has significantly added to the available observations of the Martian thermosphere by providing both in-situ [e.g. Mahaffy et al., 2015a] and remote [e.g. Jain et al., 2015] observations taken systematically across a range of conditions [Jakosky et al., 2015].

However, prior to the beginning of wind measurements in 2016 by the NGIMS (Neutral Gas and Ion Mass Spectrometer) instrument onboard MAVEN [Benna et al., 
2019], no in-situ observations of thermospheric winds existed (see review by Bougher et al. [2017a]). The few previous indirect measurements of thermospheric winds available include zonal wind speeds unfolded from MGS accelerometer and rate data during the 1997-1998 Noachis dust storm event, in which wind speeds up to $200 \mathrm{~m} / \mathrm{s}$ were estimated [Baird et al., 2007]. Characteristics of horizontal wind circulation patterns in the upper atmosphere have also been inferred from nightglow emission distributions [e.g. Gagné et al., 2013; Stiepen et al., 2017].

Most of the current understanding of the expected Martian thermospheric winds is derived from 3-D GCMs (general circulation models) (see review by Bougher et al. [2017a]). One such GCM is the Mars Global Ionosphere-Thermosphere Model (M-GITM) [Bougher et al., 2015b], used in the present study. Ground-to-exobase GCMs produce global circulation patterns and thermal structures expected for the thermosphere and thus can help overcome limited spatial and temporal coverage of observational data as well as, based on the physics included in the model, provide information about atmospheric processes not available from observations. However, simulated thermospheric winds have remained largely unconstrained due to the lack of comprehensive, and particularly, in-situ wind measurements (see review by Bougher et al. [2017a]).

Many Mars GCMs that extend into the thermosphere generally show a large-scale circulation pattern at these altitudes where strong winds transport heat and energy from the summer to winter hemisphere as well as from dayside to nightside [e.g. GonzálezGalindo et al., 2010; Bougher et al., 1999; Winchester and Rees, 1995]. This general behavior is also seen in simulations from M-GITM [Bougher et al., 2015b]. Under typical conditions, it is largely expected that pressure gradients set up by differential heating from in-situ absorption of EUV radiation drive the thermospheric circulation, which is also steered by the Coriolis effect. Note that the EUV flux and associated thermospheric heating vary with season and solar cycle [Forbes et al., 2008]. Thus, the thermospheric circulation is expected to change over these timescales in response, as suggested by modeling studies [e.g. Bougher et al., 2015b; González-Galindo et al., 2009].

It has become increasingly apparent that winds play an important role in the thermosphere. Both modeling and observational studies of the Martian upper atmosphere have suggested an intricate system of feedbacks between dynamical, energetic, and chemical processes [Bougher et al., 2017a]. For instance, while solar EUV heating in the thermo- 
sphere is believed to be offset primarily by cooling from thermal conduction (above $\sim 130$ $\mathrm{km}$ ), to a lesser degree, horizontal advection and adiabatic cooling (due to upwelling associated with divergence of horizontal flow) can also contribute [Bougher et al., 1999]. The global scale circulation also impacts atmospheric composition in the upper atmosphere. For example, $\mathrm{N}$ and $\mathrm{O}$ atoms produced on the dayside are transported to the nightside by the general circulation where they combine into $\mathrm{NO}$ and produce observed nightglow emissions [e.g. Bertaux et al., 2005; Stiepen et al., 2017]. The influence of the global circulation on thermospheric composition can also be inferred from observations of a helium bulge on the nightside of Mars [Elrod et al., 2017]. Helium is enhanced in this region due to the global circulation pattern which gives rise to large-scale convergence of horizontal winds and vertical downwelling, bringing Helium down from altitudes where diffusive separation causes it to be relatively more abundant [Liu et al., 2014; Keating and Prior, 1968].

These, among other observations and modeling results strongly suggest that the dynamics of the upper atmosphere are complex and that thermospheric winds are strongly interconnected with other atmospheric processes and parameters. Thus, understanding wind patterns and their temporal variability in the Martian upper atmosphere is key to understanding the physical processes occurring in the thermosphere and their interactions. Data-model comparisons are an important method of improving this understanding.

To address this need, during the extended MAVEN mission, a new technique was developed which gave the NGIMS instrument the capability to measure horizontal neutral winds along and perpendicular to the spacecraft track. Notably, these are the first in-situ, direct measurements of thermospheric winds at Mars [Benna et al., 2019]. By comparing this unique dataset to model simulations, physical processes that significantly contribute to driving the thermospheric winds and their variability can begin to be better identified as well as their relative importance under different conditions.

The rest of this paper will discuss the results of data-model comparisons using NGIMS wind observations and M-GITM simulations. In section 2, the NGIMS wind observational technique and the M-GITM model will be described and the methodology behind the comparison will be outlined. In section 3, the results of the comparison will be shown, and in section 4, the implications of those results concerning the role of solar forcing and 
other physical processes in driving the winds will be discussed. Finally, section 5 will summarize the main conclusions of this analysis.

\section{Method}

\subsection{NGIMS Neutral Wind Observations}

The NGIMS instrument is a quadrupole mass spectrometer originally designed to characterize the composition of the upper atmosphere and ionosphere of Mars [Mahaffy et al., 2015a; Benna et al., 2015]. The instrument collects its measurements by sampling neutral and ion species through two inlets and then utilizes a quadrupole mass filter. Further details of the NGIMS instrument and normal operations can be found in Mahaffy et al. [2015b].

In 2016, following two years of operations, a new observational technique was developed that enabled the NGIMS instrument to take regular measurements of horizontal neutral winds. During this mode, the normal data collection of NGIMS is paused to allow for wind observations to be conducted. The new wind measurement mode relies on the ability of the MAVEN spacecraft to rapidly and continuously vary the boresight pointing by nodding the articulated payload platform (APP) on which NGIMS is mounted back and forth by $8^{\circ}$ off the spacecraft ram direction. Wind velocities were extracted from the observed modulations of neutral and ion fluxes as the instrument pointing direction changed. The data reduction procedure is detailed in [Benna et al., 2019].

The resulting wind measurements were retrieved along an altitude range of around $140-240 \mathrm{~km}$. Measurements were separated by the 30 seconds it takes for the instrument boresight to complete a full motion cycle. Reconstructed along- and across-track wind magnitudes have a random uncertainty typical of $20 \mathrm{~m} / \mathrm{s}$ and $6 \mathrm{~m} / \mathrm{s}$, respectively. These uncertainties are mainly due to inherent errors in the reconstructed ephemeris of the spacecraft and the direction of the instrument boresight, in the energy resolution of the instrument's mass filter, and in counting statistics. Counting errors follow a Poisson distribution, errors from the quantization of analyzer steps follow a uniform distribution, and errors in reconstructed instrument pointing follow a normal distribution. Furthermore, if the wind fluctuates on timescales shorter than the 30 seconds it takes to nod the APP, this also adds to the overall uncertainty in the measurements. During the wind measurement retrieval process, the modulation seen by NGIMS during the 30 seconds it takes the APP 
to complete a motion cycle is compared to the expected modulation if constant winds are assumed. Poor fits to the expected modulation over 30 seconds would indicate uncertainties are greater than the values stated above [Benna et al., 2019]. However, in all of the data points examined in this study, negligible variability was seen on the scale of seconds. This indicates no appreciable additional uncertainty was added on due to poor quality observations. The dataset of zonal and meridional wind measurements is a NGIMS Level 3 data product. Version 3, release 1 data was used (v03_r01).

Most wind measurements were collected in monthly campaigns. During a typical two to three day campaign, NGIMS conducted a set of consecutive 5-10 orbits of neutral wind observations over the same local time, latitude, and altitude region (but different longitudes). For the purpose of comparing to the M-GITM model in this study, these 5-10 consecutive orbits were averaged to produce a campaign-average profile. This is a basic average of all velocity data points at a given latitude, local time, and altitude location over the time period of the campaign. Since very small differences exist in a sampling location in latitude, local time, and altitude from orbit to orbit due to the way in which the timing of periapsis is determined, NGIMS data was interpolated to the exact same locations before averaging. Note that for the profiles, averages were only calculated for the altitudes within the segment of the spacecraft's track which were sampled in all the orbits of a campaign. Campaign averaging is effectively also a longitudinal average, as the MAVEN periapsis traverses the planet in longitude once about every five orbits [Jakosky et al., 2015], which is the typical length of a wind campaign. Thus, averaged over a campaign, any potential longitudinal variability in the winds should largely be smoothed out.

To examine the orbit-to-orbit variability potentially smoothed out by the averaging, the standard deviation of the measured velocities along the spacecraft's track was also calculated. The standard deviation of the zonal and meridional components over a campaign was found first, then this was used to find profiles of the zonal and meridional flow corresponding to 1- $\sigma$ variability about the mean. These were then transformed to speed and direction and used to find a corresponding standard deviation in speed and direction.

While standard deviation can show the amount of variability in wind speed versus that of direction, another calculated statistical quantity called the coefficient of variation takes into account the coupled relationship between the two. The coefficient of variation provides a dimensionless scalar measure of the orbit-to-orbit variability of the winds re- 
lated to both variability in direction and magnitude. The multivariate version of the coefficient of variation was determined from zonal and meridional components of the wind observations using the formulation from Albert and Zhang [2010]:

$$
C V=\left[\mu^{T} \Sigma \mu /\left(\mu^{T} \mu\right)^{2}\right]^{1 / 2}
$$

where $\mu$ is the mean and $\Sigma$ is the variance-covariance matrix of the zonal and meridional components. Higher coefficients of variation can correspond to higher variability in either direction or speed, or variability in both. A minimum coefficient of variation value of zero indicates there is no orbit-to-orbit variability, while the higher the value, the more variability is present.

\subsection{M-GITM Simulations}

The general circulation model used in this study is the Mars Global IonosphereThermosphere Model (M-GITM). M-GITM is a finite difference 3-D spherical model developed to address the physics of the entire Mars atmosphere from the surface to $\sim 250$ $\mathrm{km}$. Specifically, M-GITM was designed to accurately represent the observed thermosphereionosphere structure and allow investigation of the coupling of the thermosphere-ionosphere to the lower atmosphere and exosphere [see Bougher et al., 2015b]. The M-GITM framework is built from the terrestrial GITM framework [Ridley et al., 2006] with Mars-specific fundamental physical parameters, ion-neutral chemistry, and radiative processes. M-GITM uses an altitude based vertical coordinate, allowing for a relaxation of the assumption of hydrostatic equilibrium. As a result, while horizontal neutral winds are solved in bulk, the momentum equation is solved separately in the vertical direction for each major species [Bougher et al., 2015b]. M-GITM was run with a $5^{\circ}$ resolution in latitude and longitude and a constant $2.5 \mathrm{~km}$ vertical resolution.

For the Mars lower atmosphere $(0-80 \mathrm{~km})$, M-GITM includes radiative processes and a basic dust distribution. For these altitudes, a correlated-k radiation code adapted from the NASA Ames Mars General Circulation Model (MGCM) [Haberle et al., 2003] is used. This provides M-GITM with solar heating, variable aerosol heating, and $\mathrm{CO}_{2} 15 \mu \mathrm{m}$ cooling for the region of the atmosphere in local thermodynamic equilibrium (LTE). A fast formulation of surface temperatures adapted from MGCM and based on Mars empirical temperatures is also included. Additionally, a basic dust scheme was included which 
uses a globally uniform and seasonally averaged visible dust opacity of $\tau=0.5$. For vertical extent of the dust, a Conrath parameterization scheme is used in which the dust is well mixed below a particular altitude and decays exponentially above [Conrath, 1975].

For the upper atmosphere $(\sim 80-250 \mathrm{~km})$, M-GITM includes a formulation for nonlocal thermodynamic equilibrium (NLTE) $\mathrm{CO}_{2} 15 \mu \mathrm{m}$ cooling, appropriate EUV and IR heating rates, and ion-neutral chemistry [Bougher et al., 2015b]. Along with the $15 \mu \mathrm{m}$ $\mathrm{CO}_{2}$ cooling code, a correction for NLTE near-IR heating rates near the $\sim 80-120 \mathrm{~km}$ region of the upper atmosphere was included. The EUV-UV heating routines utilized in MGITM are appropriate for a $\mathrm{CO}_{2}$ atmosphere, using the relevant set of cross-sections and yields. This includes those specified for in-situ heating by EUV-UV, dissociation, and ionization rates over altitudes from $\sim 80-250 \mathrm{~km}$ [Bougher et al., 2015b]. Additionally, over thirty key ion-neutral chemical reactions and associated rates [Fox and Sung, 2001] are used by M-GITM. Photochemical equilibrium is assumed for solving for the ionosphere in M-GITM. It should be noted that for the M-GITM simulations here, topography, the effects of the Martian crustal magnetic fields, and ion-neutral drag have not been implemented within the code.

Comparisons have been conducted between M-GITM simulations and MAVEN measurements over the first two years of the spacecraft's science mission. This includes comparisons for the first six Deep Dip campaigns (in which periapsis is lowered to $~ 125$ km) [Bougher et al., 2015c; Zurek et al., 2017] and dayside science orbits [Bougher et al., 2017b]. These and other NGIMS/M-GITM comparisons have revealed M-GITM captures the basic dayside density variations in key species as well as temperatures at low solar zenith angles, where solar forcing would be expected to be the dominant mechanism controlling thermospheric structure. Yet other comparisons, such as those with mass densities derived from MAVEN accelerometer measurements in Zurek et al. [2017], have shown that data-model comparisons are poor from midnight through the dawn terminator.

Notably, two recent upgrades have been included in the M-GITM code to improve data-model comparisons. First, a more realistic $\mathrm{CO}_{2}$ NLTE $15 \mu$ m cooling scheme used in González-Galindo et al. [2013] and Medvedev et al. [2015] has been implemented in MGITM to accurately capture the feedback of atomic $\mathrm{O}$ densities and large diurnal temperature variations on the cooling rates. Similar to what was observed by González-Galindo et al. [2013] with the inclusion of this code into the LMD MGCM (Laboratoire de Météorolo- 
gie Dynamique Mars GCM) [Angelats i Coll et al., 2005], by adding this new scheme into M-GITM, temperatures near the mesopause are cooler (see also McDunn et al. [2010]), which is in better agreement with the stellar occultation observations from the Spectroscopy for Investigation of Characteristics of the Atmosphere of Mars (SPICAM) instrument on Mars Express seen in Forget et al. [2009]. While this had little impact on the dayside thermospheric temperatures, it did decrease temperatures on the nightside even up to thermospheric altitudes. Overall, this scheme is a more accurate representation of the cooling process, particularly in the mesosphere and lower thermosphere regions.

The second upgrade incorporates the capability in M-GITM to make use of output from the FISM-M (Flare Irradiance Spectral Model - Mars) empirical model. FISM-M uses the solar EUV fluxes measured at Mars by the MAVEN EUVM (Extreme Ultraviolet Monitor) instrument to yield daily averaged full solar spectra from $\sim 0-190 \mathrm{~nm}$ in $10 \mathrm{~nm}$ bin intervals [Thiemann et al., 2017]. The wavelength bins used by M-GITM were populated with these daily averaged datasets. This provides M-GITM with solar EUV fluxes corresponding to MAVEN-specific orbit measurements, allowing for a more accurate representation of solar forcing during each wind campaign. The FISM-M datasets used here were the Level 3 EUV daily products v10_r01 (for the first two campaigns) and v11_r04 (for the last three campaigns).

This upgraded M-GITM was run for the duration of the time periods corresponding to five NGIMS wind campaigns. With the newly incorporated FISM-M output, simulations of each different campaign have solar fluxes and seasonal conditions that, in as direct a manner as currently possible, correspond to those that occurred during each campaign. From these M-GITM simulations, winds were extracted along the same track flown by the MAVEN spacecraft (in latitude, altitude, and local time) using the spacecraft's trajectory information for each orbit in the campaign. These model flythroughs allow for a more direct comparison of M-GITM output to the in-situ NGIMS wind observations. Additionally, while extracting the flythroughs from any given orbit, the areocentric coordinate system natively used by M-GITM was converted to an areodetic coordinate system used by NGIMS, which slightly changes the way in which altitude is determined based on whether the planet is considered spherical or an oblate spheroid, respectively, in these coordinate systems (for more information on the coordinate system used by MAVEN, see Seidelmann et al. [2002]). Finally, these M-GITM flythroughs were averaged over the entire campaign (still differentiating between inbound and outbound segments of the orbit), 
in the same way as the averaging was done with the NGIMS wind profiles, to create a campaign-averaged profile. In this process, to facilitate campaign averaging, M-GITM flythroughs were also interpolated to the same points in latitude, local time, and altitude as was done for the NGIMS profiles. Differences in the averaged simulated and observed velocity profiles were then calculated.

Note that averaging M-GITM flythroughs over the length of the campaign is primarily done to match the process used for the NGIMS data, and not because there is large intrinsic orbit-to-orbit variability produced by M-GITM. However, in the NGIMS data, as will be shown in later sections, the orbit-to-orbit variability can be very large. Averaging the NGIMS data over every orbit in a campaign, then, is done so that an average flow in that location might be identified, compared to the model, and examined for any trends over longer time periods.

\section{Results}

The first analysis of observations from NGIMS wind campaigns was presented by Benna et al. [2019]. In the current study, five NGIMS neutral wind campaigns were selected for further analysis in comparison with the upgraded M-GITM simulations described in section 2.2. These specific campaigns - September 2016, January 2017, May 2017, December 2017, and February 2018 - were chosen so that campaigns spanning a range of latitudes, local times, and seasons would be represented in this analysis. Geophysical conditions for these select campaigns are included in Table 1.

In general, these data-model comparisons show that NGIMS neutral wind measurements in some cases are similar to M-GITM simulated winds, but in others do not match in speed, direction, or both. Campaign averaged speeds from NGIMS and the corresponding MGITM simulations are displayed in Table 2 and campaign averaged directions can be found in Table 3.

\subsection{September 2016 Campaign}

The September 2016 campaign was the first NGIMS wind campaign consisting of five consecutive orbits of neutral wind measurements over the course of two days. This campaign occurred over the southern mid-latitudes on the dayside, near the evening terminator, and near perihelion (see Table 1). Campaign averaged profiles are included in 
Figure 1, which show the direction and speed for both NGIMS observed winds (in blue) and M-GITM simulated winds (in red) as well as profiles that show the difference between the two (in purple). NGIMS observed high speeds during this campaign, on average over $300 \mathrm{~m} / \mathrm{s}$ (see Table 2), which did not deviate much in direction throughout the entire altitude range. The September 2016 campaign saw a prevailing direction primarily to the north-northeast (or NNE, in the standard abbreviated directional notation, which will be used from this point forward), also seen in Figure 2, which shows velocity vectors from NGIMS observations along the spacecraft's track in latitude and local time.

As seen by the gray vectors plotted in Figure 2, measurements from each orbit are all largely consistent with each other. This can be demonstrated quantitatively by the coefficient of variation (described in section 2.1), which is included in Table 4 for all campaigns and represented by the color of the campaign averaged vectors in Figure 2. Coefficient of variation values uniformly below 0.31 (compared to a maximum value of 1.92 seen over all selected campaigns) indicate very little orbit-to-orbit variability was observed in the September campaign.

Notably, the directions of the NGIMS observed winds and the M-GITM simulated winds are very similar. This can be seen in the profiles in Figure 1 and in comparing the colored averaged NGIMS and black averaged M-GITM vectors in Figure 2. Data and model wind directions are within $25^{\circ}$ of each other throughout the altitude profile, and less than five degrees apart at periapsis. Both the observed and simulated wind headings also turn slightly more to the northwest or north, respectively, along the spacecraft track (approaching later local times and lower latitudes). Yet, with a simulated speed at about $160 \mathrm{~m} / \mathrm{s}$ (averaged over the campaign and over all altitudes), M-GITM seems to be underpredicting the observed speed by over $150 \mathrm{~m} / \mathrm{s}$.

\subsection{January 2017 Campaign}

The January 2017 campaign lasted three days and consisted of ten consecutive orbits of neutral wind measurements. This campaign took place at a similar season and latitudes as the September 2016 campaign (see Table 1). Unlike the September 2016 campaign, the January 2017 campaign occurred at local midnight. As seen in the profiles in Figure 3, this campaign has much lower wind speeds than in the September 2016 case, with a campaign and profile average of $\sim 60 \mathrm{~m} / \mathrm{s}$. In contrast, M-GITM simulations are producing 
average horizontal wind speeds of $\sim 260 \mathrm{~m} / \mathrm{s}$. In addition to this $\sim 200 \mathrm{~m} / \mathrm{s}$ difference in speed, the NGIMS averaged direction is over $90^{\circ}$ separated from the M-GITM flythrough direction, with averaged NGIMS observed winds directed generally to the S to SW and M-GITM simulated winds to the NW.

However, this difference in direction and speed is impacted strongly by the large orbit-to-orbit variability in the NGIMS measurements seen in Figure 4. The coefficient of variation for this campaign ranges from 0.72 to 1.92 - values much greater than in the September 2016 campaign. Not only does the direction (and to a lesser extent, speed) vary widely between each orbit, but also between each sampling point (represented in Figure 4 by individual gray vectors). Both overall lower speeds and an average of vectors with very different directions contributes to the low average speeds. The lack of any persistent wind direction also perhaps implies the average direction is less meaningful in this campaign. This high orbit-to-orbit variability is not only extremely different than the consistency observed in the September 2016 campaign, but is also an extreme case among all of the NGIMS wind campaigns.

\subsection{May 2017 Campaign}

The May 2017 campaign occurred shortly after northern hemisphere spring equinox in the northern mid-latitudes. These ten consecutive orbits sampled the dayside, right before local noon. On average, over the campaign and all altitudes, this campaign observed wind speeds $\sim 120 \mathrm{~m} / \mathrm{s}$ and directions toward the E to SSE, as seen in Table 2 and Figure 4 respectively. In this campaign, wind speeds increase away from spacecraft periapsis on the outbound leg (at higher altitudes, lower latitudes, and closer to noon local time). The wind direction also shifts from eastward to southeastward along the track. Though separating the effects of altitude, latitude, and time is difficult due to the nature of the spacecraft's track, based on the altitude profiles in Figure 3, this shift in heading does not seem to be as much a function of altitude, but rather one of latitude or local time.

Looking at the coefficient of variation values in Figure 4, this campaign had less orbit-to-orbit variability than the January 2017 campaign, but more than the September 2016 campaign. Coefficient of variation values are greatest (approaching 1.3) near periapsis. The lower average wind speeds at periapsis altitudes are a result of both overall lower 
speeds in this section of the orbit as well as increased directional variability, somewhat similar to what was seen throughout the January 2017 campaign.

Significantly in this campaign, and clearly seen by the profiles showing direction in Figure 3, NGIMS observed wind directions and M-GITM simulated flythrough directions are nearly $180^{\circ}$ apart throughout much of the sampled track. This difference in direction between simulations and observations is smallest in the inbound leg of the orbit (higher latitudes and earlier local times) where averaged NGIMS winds have a greater zonal component, traveling nearly to the east. Unlike the direction, the difference in simulated and observed speeds is relatively small, only $\sim 40 \mathrm{~m} / \mathrm{s}$ on average, and in particular, for the outbound leg of the orbit, reaches $0 \mathrm{~m} / \mathrm{s}$ difference.

\subsection{December 2017 Campaign}

The December 2017 campaign occurred during the aphelion season over the southern hemisphere, low-latitude, late-morning dayside. During this campaign, the averaged magnitude of the winds reached $200 \mathrm{~m} / \mathrm{s}$ while the direction was primarily to the WNW. As seen in Figure 8, very little turning of the averaged observed winds occurs except at lower latitudes and later local times, where a slightly stronger northward component is introduced. Additionally, the averaged speeds for this campaign are faster near periapsis.

Relatively small orbit-to-orbit variability is seen in this campaign, as implied by the lower values of the coefficient of variation in Figure 8 ( 0.28 on average). Only a couple of the orbits out of the five in the campaign provided most of that variation, while the remaining orbits were largely consistent with each other.

In this campaign, comparing with the corresponding M-GITM flythrough, the direction of the simulated winds is less than $90^{\circ}$ apart (Figure 7). Both M-GITM and NGIMS show winds primarily directed westward, though the observed winds have a minor northward component, while the simulated winds instead have a southward component in their heading. In addition, averaged over the campaign and profile at $157 \mathrm{~m} / \mathrm{s}$, M-GITM predicts slower speeds than observed with NGIMS by $\sim 45 \mathrm{~m} / \mathrm{s}$. 


\subsection{February 2018 Campaign}

Similar to the January 2017 campaign, the February 2018 campaign consisted of ten consecutive orbits taking observations near local midnight at southern mid-latitudes. The February 2018 campaign, however, occurred late in the aphelion season. In this campaign, averaged winds were slightly faster than the December 2017 campaign, at $221 \mathrm{~m} / \mathrm{s}$. As seen in Figure 10, the averaged winds in the February 2018 campaign do shift (from a NNE to a NNW heading) as the sampling progresses to lower latitudes and later local times.

There was a moderate amount of orbit-to-orbit variability observed in this campaign (as seen in Figure 10), though more strongly present in magnitude than direction. However, this case still had more orbit-to-orbit consistency in the flow than the January 2017 campaign, as seen by an average coefficient of variation of 0.52 .

Notably, the difference in direction between observed and simulated winds in this campaign is relatively small, on average about $35^{\circ}$ (see Figure 9). Both observed and simulated averaged speeds show a strong northward component. Headings match most closely at the lower latitudes and later local times of the outbound leg of the orbit, where both simulated and observed speeds are directed NW. Unlike the averaged direction, MGITM does not well replicate the average speed. With a flythrough average of $\sim 130 \mathrm{~m} / \mathrm{s}$, M-GITM underpredicts speed by nearly $100 \mathrm{~m} / \mathrm{s}$.

\section{Discussion}

\subsection{Analysis of selected NGIMS wind campaigns and M-GITM comparisons}

These NGIMS campaigns include a range of cases from those in which M-GITM can, to a large extent, replicate observed wind velocities to those in which M-GITM is not capturing observed winds at all. In section 3, it was seen that for the September 2016 campaign, M-GITM very closely replicated direction (which on average differed by $25^{\circ}$ at most), but was underpredicting average speed by $\sim 150 \mathrm{~m} / \mathrm{s}$. Similarly, in the February 2018 campaign, simulated and observed directions are reasonably close, while M-GITM suggests an average speed almost $100 \mathrm{~m} / \mathrm{s}$ less than what was observed. The May 2017 campaign, on the other hand, shows M-GITM producing averaged speeds only $\sim 40 \mathrm{~m} / \mathrm{s}$ different from those observed by NGIMS. The averaged direction in this case, however, was roughly $180^{\circ}$ opposing. The December 2017 campaign showed a general agreement 
in the direction of the main component of the velocities, and had a $\sim 45 \mathrm{~m} / \mathrm{s}$ difference in averaged speed. The most disparate of these cases was the January 2017 campaign, in which M-GITM overpredicted speeds by more than $200 \mathrm{~m} / \mathrm{s}$ on average and did not match the average direction either. Thus, there are cases where observed and simulated speeds are similar but directions are not, those where direction is similar, but speed is not, and one where neither is replicated by the model.

Significantly, the M-GITM model is currently primarily driven by solar forcing at thermospheric altitudes [Bougher et al., 2015b; Bougher et al., 2017b]. No other processes included in the model have as large of an impact in driving thermospheric behavior as EUV heating. Inclusion of physics in M-GITM that accurately represent the effects of typical in-situ solar forcing at these altitudes (see section 2.2) was particularly emphasized in developing the model due to the importance of EUV heating in the thermosphere (see section 1). (Note that by typical or normal solar forcing, we mean the impact of background solar conditions on the atmosphere without any possible effects from large transient phenomena such as solar flares.) Due to the emphasized capabilities of the model in regard to normal solar forcing, this implies that a likely interpretation for cases of data-model agreement is that differential heating resulting from absorption of EUV radiation is the process most strongly responsible for driving the observed thermospheric winds.

Figures 11, 12, and 13 show temperatures and horizontal winds at a constant altitude $(170 \mathrm{~km})$ over latitude and local time from M-GITM simulations corresponding to September 2016, May 2017, and December 2017. These cases in turn correspond to near perihelion, near equinox, and near aphelion conditions, respectively. The effects of solar forcing in M-GITM can be seen as, in general across all seasons, the model suggests a horizontal circulation in which the winds flow away from the subsolar point and converge on the nightside. The first analysis of all available NGIMS wind campaigns presented by Benna et al. [2019] also described a general dayside to nightside flow that was observed in many of the campaigns.

In the September 2016 campaign, the significant directional agreement between simulated and observed winds suggests that during this time period, differential solar heating is likely the primary mechanism driving the thermospheric winds. Recall that this campaign occurred near the evening terminator on the dayside near perihelion. During the perihelion season, solar forcing in the thermosphere would be expected to be stronger due to 
the increase in solar flux received when Mars is closer to the Sun, resulting in a warmer summer and a more intense diurnal cycle [González-Galindo et al., 2009]. In Figure 11, M-GITM produces a fairly high-speed circulation in the mid-southern latitudes near the evening terminator where the September 2016 campaign took place. This flow pattern produced by M-GITM is likely representative of actual conditions near the time and in the general vicinity of this MAVEN campaign as indicated by the substantial agreement of the model flythrough with the observed direction.

Likewise, the agreement in average direction for the February 2018 campaign implies this is probably another case where normal solar forcing is strongly driving the winds at this time and location. Looking at Figure 13 (though it is from the December 2017 simulation, it occurs in the same season as the February 2018 campaign and thus, the plot is not discernably different), M-GITM suggests that at these high-southern latitudes on the nightside, there is a strong northward flow coming over the south pole from the dayside. Again, the strong directional agreement between simulations and observations suggests the winds at this time and location are following the circulation pattern produced by MGITM, established by differential heating. Solar forcing appears to be largely driving the winds for this campaign even during the aphelion season, when Mars is at a greater distance to the Sun. Even in the December campaign, winds seem to generally follow the expected circulation pattern in that location, so similar to the winds simulated by M-GITM, are likely driven primarily by normal solar forcing (Figure 13).

Yet even these three cases where data-model agreement in wind direction seems to indicate the importance of the role of solar forcing, the model is not replicating the magnitude of the winds. This suggests that while solar forcing might play the most important role during these campaigns, other processes are still modifying the winds, and particularly in these campaigns, their speeds.

It should be noted that temperatures in the Martian upper atmosphere are believed to vary with the solar cycle [e.g. Forbes et al., 2008; Bougher et al., 2017a] and modeling studies have suggested the solar cycle should impact thermospheric winds as well [e.g. Bougher et al., 2009, 2015b]. However, all five of these campaigns occurred during near solar minimum conditions. Thus, the change in solar flux and any corresponding heating due to the eleven-year solar cycle is not likely driving the thermospheric winds in these cases. 
In contrast to the above three cases, the January and May 2017 campaigns show significant directional disagreement when compared to the M-GITM simulated winds. The disparity observed in the data-model comparisons for these campaigns suggests that not only is normal solar forcing not the primary mechanism acting on the winds, but the processes modifying them are those that M-GITM is lacking or handles poorly.

The January 2017 campaign stands out as the worst match to its corresponding MGITM flythrough in both wind direction and speed. From Figure 11 (using the September 2016 perihelion plot as a close proxy), M-GITM predicts a very high-speed flow in this vicinity due to a circulation from the subsolar region across the south pole to the nightside. This does not at all represent the velocities observed by NGIMS. With NGIMS campaign average speeds of near $35-80 \mathrm{~m} / \mathrm{s}$ at $170 \mathrm{~km}$ (and on average $56 \mathrm{~m} / \mathrm{s}$ throughout the profile), some mechanism is significantly slowing down and modifying the wind direction from the flow expected from the predominately solar-driven M-GITM simulations. This mechanism could be related to the extreme variability in the winds during this campaign. Implications of this variability and data-model comparisons will be discussed further in section 4.3.

As mentioned in section 2.1, during the wind measurement retrieval process, any modulation during the 30 seconds it takes for the APP to nod once is compared to the expected modulation if constant winds are assumed. This comparison provides a measure of variability of the wind on a scale of a few seconds. During the January 2017 campaign, while the winds exhibited very large variability on the scale of hours (perceptible in the orbit-to-orbit comparison), they did not show appreciable variability on the scale of seconds. This increases confidence in the quality of these observations while additionally providing a time scale restraint for identifying processes that could be producing this variability.

In the May 2017 campaign, wind headings are observed that are on average $\sim 180^{\circ}$ apart from the winds expected in M-GITM. While some variability is present in this campaign, it is not present to the extent observed in the January 2017 campaign. Most, though not all, orbits show a prevailing direction to the E to SE. Examining Figure 12, it can be seen that M-GITM, in this location (mid-northern latitudes on the dayside prior to local noon), produces a meridional flow that is directed northward as a part of a transpolar flow from the subsolar point to the nightside and a zonal flow that is westward, again from sub- 
solar point to nightside. The reverse direction in the flow seen in the NGIMS observations with only a moderate amount of orbit-to-orbit variability suggests there is a completely different circulation pattern set up at the specific time and location of this campaign. It is possible another physical process not included in the model is dominating and reversing the expected flow driven by normal solar forcing and predicted by M-GITM.

\subsection{Local time and seasonal effects}

A few campaigns occur at similar local times, latitudes, or seasons. This overlap makes it possible to try to examine the influences of different geophysical conditions. For example, both the January 2017 and the September 2016 campaigns occurred near perihelion so had very similar solar declination angles and also tracked over near the same mid-southern latitudes. However, while the September 2016 campaign was on the dayside near the evening terminator, the January 2017 campaign occurred at local midnight.

Since the January 2017 campaign differs from the September 2016 campaign in local time, but is similar in other geophysical conditions, it might seem that the physical processes the model isn't representing well in the January 2017 campaign are dependent on local time and act more strongly on the nightside of Mars where that campaign occurs. A similar phenomenon with nightside M-GITM simulations has been noted in a study by Zurek et al. [2017]. In this study, densities derived from the accelerometer on MAVEN closely matched simulated densities on the dayside but did not well replicate the accelerometer calculations on the nightside (especially the midnight to dawn sector where the orbit-to-orbit variability was significant). This might suggest M-GITM is missing fundamental physics on the nightside of the planet which play a large role in altering the upper atmospheric flow.

The February 2018 campaign might also be compared to the January 2017 campaign since both occurred at mid-southern latitudes at or slightly after local midnight. The February 2018 campaign occurred near aphelion while the January 2017 campaign occurred near perihelion. It is possible that some of the observed differences in the flow patterns of these two campaigns are due in part to seasonal effects. However, like the September/January comparison above, the February 2018 campaign rather closely matches the expected direction from M-GITM while the January 2017 campaign is again very different. This brings into question whether a local time or seasonal dependency is primarily 
creating the differences seen in the September/January cases, or if this is just showing the unique nature of the January 2017 campaign. Thus, no clear seasonal or local time trend can be determined with just these few campaigns.

\subsection{Variability}

As discussed in section 3.2, extremely high orbit-to-orbit variability was observed in the January 2017 campaign. Since no preferential direction is observed but only variability on very short time scales, it is not particularly surprising that M-GITM is producing such a different direction than seen with NGIMS. M-GITM would not be expected to replicate extremely short timescale variability since within the physics included in the model, the shortest time scale fluctuations come from the FISM-M fluxes, but even these are interpolated daily averages. The physical process (or processes) acting on the winds in this campaign to create this level of variability on short time scales is not one included in M-GITM.

The lack of significant orbit-to-orbit variability generated in M-GITM simulations can be seen in the average standard deviations of speed and direction for the M-GITM flythroughs in Tables 2 and 3. For these campaigns, a $1-\sigma$ around $3-4^{\circ}$ for direction and 2-3 $\mathrm{m} / \mathrm{s}$ for speed is typical for M-GITM. These standard deviations are several factors smaller than the $1-\sigma$ values calculated for speed and direction for the NGIMS wind observations. One exception is the higher standard deviation of speed seen in the September 2016 MGITM flythrough, at $12 \mathrm{~m} / \mathrm{s}$ averaged over the profile. This larger standard deviation is due to the small changes in local time of the spacecraft's track each orbit combined with the proximity of the campaign to the evening terminator, which is one region where the model does generate more variability due to changes in flow surrounding a zone of converging winds.

Campaign averaged NGIMS velocity profiles were computed in this study in order to make the in-situ NGIMS wind observations more comparable to what is essentially a climate model (with the notable exception of the use of FISM-M daily fluxes). Through this averaging of at least five consecutive orbits, some of the high-frequency variability due to changing weather and potential variability due to longitudinal effects should be averaged out. However, in some cases, particularly the January 2017 NGIMS campaign, the variability is persistent, even over a period of 10 orbits (two to three Earth days). This sug- 
gests that over several orbits, localized processes or those occurring on shorter time scales can dominate the expected solar forcing driven circulation pattern. Particularly in the January 2017 case, it also seems that potential trends due to seasonal, local time, and latitude effects are being overwhelmed by another sort of forcing that is specifically occurring during this campaign. Since this extreme variability is not seen in any of the other selected campaigns, it could be that these processes driving the neutral thermospheric winds and their variability in the January 2017 campaign are extremely specific to that combination of local time, latitude, season, or other geophysical parameters.

In general, it is found that there is a relationship between variability and how well the NGIMS wind observations agree with M-GITM simulated winds. Looking at Table 4, the NGIMS campaigns with the highest average coefficient of variation, January 2017 and May 2017, are those where M-GITM is not capturing any part of the averaged observed direction, and for the January 2017 case, this is also true for the average speeds. The two campaigns with the smallest average coefficient of variation, September 2016 and December 2017, have an extremely close match in direction, and a general agreement in the heading of the main component, respectively, compared to the corresponding model simulations. Again, this miss-match between simulations and observations in these cases with high variability is to some extent expected as M-GITM lacks many of the high-frequency time dependent processes that might allow it to simulate this level of change over shorter time scales and only has spatial scales allowed by its resolution. However, it also implies that normal solar forcing may have a less dominant role in driving the thermospheric winds when this level of variability is observed. Instead, other processes may have gained relevance and altered the expected flow, perhaps by introducing turbulent components.

\subsection{Averaged speed and data-model comparison}

Finally, one trend that does seem to stand out in determining the degree of similarity between thermospheric wind headings in M-GITM simulations and observations might be the averaged speed (averaged over the campaign and all altitudes). The faster the averaged speed observed by NGIMS over the campaign, the less difference between simulated and observed wind headings is seen. The September 2016 campaign has the highest averaged wind speeds of this set of campaigns, and also on average, the least difference in heading between simulated and observed winds. The January 2017 campaign, which has 
high orbit-to-orbit variability, also has on average very low speeds. The next slowest average campaign was the May 2017 case, in which there was a near $180^{\circ}$ difference between NGIMS observed winds and M-GITM flythroughs. Of the five campaigns here, it is only those where the average speed is at least $200 \mathrm{~m} / \mathrm{s}$ where the difference in direction is less than $90^{\circ}$.

This could again indicate the relative importance of the role of solar forcing in those campaigns. When the thermospheric winds are more strongly and steadily controlled by differential solar heating in the thermosphere compared to other forcing mechanisms, they might be more likely to follow the same circulation pattern suggested by the primarily solar driven M-GITM and experience less orbit-to-orbit variability.

However, the averaged NGIMS speed is not as strong of a predictor for similarity in wind magnitude as it is for heading. For instance, the September 2017 campaign has the fastest averaged speed observed by NGIMS, but M-GITM suggests winds over $150 \mathrm{~m} / \mathrm{s}$ slower, while the January 2017 campaign has the slowest averaged speed and M-GITM overpredicts speeds by over $200 \mathrm{~m} / \mathrm{s}$.

\subsection{Physical processes not represented in M-GITM}

In their comparisons of densities derived from the MAVEN accelerometer and those predicted by M-GITM, Zurek et al. [2017] mentioned that where M-GITM could not well replicate observed densities, one physical process that might be acting relatively more strongly was gravity waves. Although the effects of gravity waves are not currently included in M-GITM, internal gravity waves are expected to be ubiquitous in the atmospheres of stably stratified planets, including Mars [Yig̈it et al., 2015]. Several observational studies have identified the effects of gravity waves in the Martian thermosphere. Measurements from MGS and Mars Odyssey aerobraking around 100-150 km showed highly variable gravity wave amplitudes, with density perturbations up to $50 \%$ of the background [Fritts et al., 2006]. More recent studies from Yig̈it et al. [2015] and England et al. [2016] using observations from the NGIMS instrument on MAVEN have also observed and begun to characterize the thermospheric gravity waves up to $\sim 220 \mathrm{~km}$.

In addition, modeling studies such as Medvedev and Yigit [2012] have shown that gravity waves should have significant dynamical and thermal effects in the lower thermosphere through large gravity wave momentum deposition. Some GCM simulations have 
suggested the gravity wave drag in the thermosphere is so large that it would be expected to modify the wind distribution dramatically [Medvedev et al., 2011b,a]. Gravity waves could also have an appreciable thermal effect in the thermosphere, both from heating of the flow due to conversion of mechanical energy to heat and from heating/cooling due to divergence of the sensible heat flux [Medvedev and Yigit, 2012].

Thus, if the effects of gravity waves were included in the M-GITM model, the simulated thermospheric temperature structure would be expected to change, accompanied by modifications of the circulation pattern. This could possibly help the model to better replicate the NGIMS wind observations in some campaigns, particularly those in which it has been found that typical solar forcing is likely not the only process responsible for significantly driving thermospheric winds. However, it is likely that gravity waves are not the only physical process that M-GITM is missing or not well representing which could be modifying the winds during these campaigns.

It is also possible that some of the orbit-to-orbit or shorter time scale variability seen in some of the campaigns is a result of the effects of gravity waves. However, adding a gravity wave parameterization scheme to M-GITM will not add variability in the simulations from individual waves since these schemes are statistical averages of gravity wave effects that impact the background winds. Models such as that used in Kuroda et al. [2015] can resolve gravity waves and so might be able to be used to determine if this orbit-toorbit variability is from the effects of gravity waves being triggered at different seasons or locations.

Though M-GITM does account for dust in the Martian atmosphere in these simulations, it does so with a relatively simple scheme that assumes a time averaged and horizontally uniform dust load (see section 2.2). This would mean M-GITM is likely underpredicting the influence of dust during the dust storm season (centered around perihelion), during which regional dust storms can notably increase the dust optical depths observed in the atmosphere [e.g. Smith, 2009]. Other studies have found that dust lofted into the atmosphere by large regional dust storms significantly impacts the radiative transfer in the atmosphere, in turn affecting heating (and thus likely the atmospheric circulation) in the lower-middle atmosphere, even far away from the center of the storm [e.g. Heavens et al., 2011; Kass et al., 2016]. Since the upper atmosphere is coupled to the lower atmosphere 
[e.g. Bougher et al., 2017a], these large dust storms could also have an impact on upper atmospheric circulation, especially through the alteration of wave propagation.

Two NGIMS wind campaigns examined here which occur in the perihelion dust storm season are the September 2016 and January 2017 cases. Of these two, the effects of increased dust would be most important during the September 2016 campaign, which occurred during the decay of a larger regional dust storm (see Mars Year 33 at http://wwwmars.Imd.jussieu.fr/mars/dust_climatology/index.html on the Mars Climate Database). While the September 2016 campaign had a very close match in simulated and observed wind direction, the magnitude of the winds was significantly different. It is possible that the increased dust during this time period is modifying the winds beyond what M-GITM suggests for a yearly-averaged dust load. Incorporating a time dependent dust parameterization scheme based on the dust load observed during each specific campaign would better reflect reality and might improve model simulations.

In addition to influences from the lower atmosphere, such as gravity waves and dust storms, large solar or ionospheric events could also impact the neutral thermospheric winds. These solar events (which we differentiate from normal solar forcing) could include coronal mass ejections and flares, which impact the ionosphere and the neutral thermosphere [e.g. Fang et al., 2013; Elrod et al., 2018; Jain et al., 2018]. However, no major solar events were seen during the time periods around any of these campaigns (see the MAVEN science event list on the Planetary Data System, files maven_events_2013-12-0100-00-00_2016-11-15-00-00-00 and maven_events_2016-11-15-00-00-00_2017-02-15-0000-00).

\section{Conclusions}

Thermospheric winds at Mars are examined through comparisons of NGIMS neutral wind observational campaigns and corresponding upgraded M-GITM simulations. M-GITM simulations were produced for five NGIMS wind campaigns which occurred over several different latitudes, local times, and seasons. Model flythroughs were extracted along the same trajectory flown by MAVEN during each orbit, and the averaged NGIMS and M-GITM altitude profiles of speed and direction were compared.

Simulations for the September 2016 and February 2018 campaigns provide the best overall agreement with the velocities observed by NGIMS, though they much more closely 
match the observed direction than speed, which M-GITM underpredicts by about 100 to $150 \mathrm{~m} / \mathrm{s}$. The December 2017 campaign measurements match the corresponding simulation moderately well in both speed and direction. On the other hand, the January 2017 and May 2017 campaigns have large disparities between the observed and simulated wind velocities. For the May campaign, M-GITM produced wind directions that were nearly $180^{\circ}$ from those observed, suggesting that an entirely different circulation pattern may have formed in this vicinity than the one expected by M-GITM. The poor correspondence between data observations and model simulations in the January 2017 campaign seems to stem from the presence of extremely high orbit-to-orbit variability (as well as variability from sampling point to sampling point within an orbit). In this case, M-GITM predicts speeds over $200 \mathrm{~m} / \mathrm{s}$ faster than those actually observed.

Since M-GITM is primarily driven by solar forcing at thermospheric altitudes in the form of EUV heating, these data-model comparisons can be used to help interpret the extent of the role of solar EUV heating in driving thermospheric winds during different campaigns. As a result, a likely interpretation of data-model agreement is that solar forcing in the form of differential heating from absorption of EUV radiation at these altitudes is primarily driving thermospheric winds at these times. Data-model disagreements suggest that processes which are not well represented or completely absent from the model may gain relevance and alter the expected circulation patterns, perhaps by introducing variability in the flow.

Notably, the one parameter over these five campaigns which served as a good indicator of how well the model would replicate that particular campaign was the campaign and profile averaged observed speed. The campaigns with greater averaged observed speeds also had the least averaged difference in heading between observed and simulated winds. NGIMS campaigns with higher averaged wind speeds also tended to have less orbit-toorbit variability, as seen by smaller values of the coefficient of variation. In these cases, normal solar forcing may be driving the winds steadily and strongly enough to overcome other processes that may induce more variability in the wind.

Though some of these campaigns covered similar latitudes, seasons, and local times, no clear trends across these were identified. This is likely partially due to the small sample size of campaigns analyzed here. Trends could also be obscured by the unique nature of the extreme orbit-to-orbit variability in the January 2017 campaign. It is possible the 
processes acting in January 2017 to create this extreme variability are masking any response to normal solar forcing or trends that might be observed across season or local time. Looking at all available NGIMS campaigns that occurred in the perihelion season, near midnight local time, or at middle to high latitudes might help reveal if the behavior in the winds seen in the January 2017 campaign is related to a specific combination of geophysical conditions, or if it is due to something else entirely. In addition, a more comprehensive look at all available NGIMS wind observations in comparison to model simulations might highlight specific regions where the model routinely agrees or disagrees with the measurements, which could help identify important physical processes acting in those regions.

These data-model comparisons serve as one of the first analyses of this dataset and demonstrate both the potential benefits and challenges of comparing the new NGIMS wind observations to model simulations. These comparisons will also serve as a baseline for future analysis as new or improved physics is added to M-GITM. Gravity waves are one type of physical process not currently included in M-GITM; however, they are believed to play a significant role in the Martian thermosphere, with both large dynamical and thermal impacts [e.g. Yig̈it et al., 2015; Medvedev and Yigit, 2012]. Thus, incorporating a gravity wave parameterization scheme into M-GITM may adjust both the magnitude and the headings of the simulated winds, similarly to what was seen in Medvedev et al. [2011a] and Medvedev and Yigit [2012]. Examining data-model comparisons after the addition of a gravity wave scheme could help constrain the conditions or locations in which gravity waves gain relevance in driving the observed winds.

Comparisons between the NGIMS neutral wind dataset and a revised M-GITM model with new physics should aid in identifying the physical processes which play a significant role in driving thermospheric wind speeds and directions during these campaigns. Additional data-model comparisons and interpretation using the NGIMS wind observations and M-GITM or other Mars GCMs will be necessary, and offers a unique opportunity to improve our understanding of the behavior of the thermospheric winds at Mars and the processes responsible for driving them. 


\section{Acknowledgments}

Funding support for this research was provided by the MAVEN project, Grant NNH10CC04C. This work was also supported by NASA Headquarters under the NASA Earth and Space Science Fellowship Program - Grant 80NSSC18K1238. Funding for F. González-Galindo and M. Á. López-Valverde was provided by the Spanish National Research Council under intramural project CSIC 201450E022. NGIMS datasets used in this paper are available on the Planetary Data System (http://pds-atmospheres.nmsu.edu/data_and_services/atmospheres_data/MAVEN/ngims.html) as well as EUV datasets (https://pds-ppi.igpp.ucla.edu/search/view/?f=yes\&id=pds://PPI/maven.euv.modelled). Datacubes containing M-GITM simulations used in this paper can be found on the University of Michigan Deep Blue repository at http://doi.org/10.7302/85qt-e980.

\section{References}

Albert, A., and L. Zhang (2010), A novel definition of the multivariate coefficient of variation, Biometrical Journal, 52(5), 667-675, doi:10.1002/bimj.201000030.

Angelats i Coll, M., F. Forget, M. A. López-Valverde, and F. González-Galindo (2005), The first Mars thermospheric general circulation model: The Martian atmosphere from the ground to $240 \mathrm{~km}$, Geophysical Research Letters, 32, 4201, doi: 10.1029/2004GL021368.

Baird, D. T., R. Tolson, S. Bougher, and B. Steers (2007), Zonal wind calculations from Mars Global Surveyor accelerometer and rate data, Journal of Spacecraft and Rockets, 44, 1180-1187, doi:10.2514/1.28588.

Benna, M., P. R. Mahaffy, J. M. Grebowsky, J. L. Fox, R. V. Yelle, and B. M. Jakosky (2015), First measurements of composition and dynamics of the Martian ionosphere by MAVEN's Neutral Gas and Ion Mass Spectrometer, Geophysical Research Letters, 42(21), 8958-8965, doi:10.1002/2015GL066146.

Benna, M., S. W. Bougher, Y. Lee, K. J. Roeten, E. Yig̈it, P. R. Mahaffy, and B. M. Jakosky (2019), Global Circulation of Mars' Upper-Atmosphere, Science, doi: 10.1126/science.aax 1553.

Bertaux, J., F. Leblanc, S. Perrier, E. Quemerais, O. Korablev, E. Dimarellis, A. Reberac, F. Forget, P. C. Simon, S. A. Stern, B. Sandel, and The SPICAM Team (2005), Nightglow in the upper atmosphere of Mars and implications for atmospheric transport, Science, 307(5709), 566-569, doi:10.2307/3840002. 
Bougher, S. W., S. Engel, R. G. Roble, and B. Foster (1999), Comparative terrestrial planet thermospheres 2. Solar cycle variation of global structure and winds at equinox, J. Geophys. Res., 1041, 16,591-16,611, doi:10.1029/1998JE001019.

Bougher, S. W., T. M. McDunn, K. A. Zoldak, and J. M. Forbes (2009), Solar cycle variability of Mars dayside exospheric temperatures: Model evaluation of underlying thermal balances, Geophys. Res. Lett., 360, L05,201, doi:10.1029/2008GL036376.

Bougher, S. W., T. E. Cravens, J. Grebowksy, and J. Luhmann (2015a), The aeronomy of Mars: Characterization by MAVEN of the upper atmosphere reservoir that regulates volatile escape, Space Sci. Reviews, 195, 423-456, doi:10.1007/s11214-014-0053-7.

Bougher, S. W., D. Pawlowski, J. M. Bell, S. Nelli, T. McDunn, J. R. Murphy, M. Chizek, and A. Ridley (2015b), Mars Global Ionosphere-Thermosphere Model: Solar cycle, seasonal, and diurnal variations of the Mars upper atmosphere, J. Geophys. Res., 120, 311342, doi:10.1002/2014JE004715.

Bougher, S. W., B. M. Jakosky, J. Halekas, J. Grebowsky, J. G. Luhmann, and others (2015c), Early MAVEN dip deep campaign reveals thermosphere and ionosphere variability, Science, 350, 1-7, doi:10.1126/science.aad0459.

Bougher, S. W., D. A. Brain, J. L. Fox, F. González-Galindo, C. Simon-Wedlund, and P. G. Withers (2017a), Upper Neutral Atmosphere and Ionosphere, p. 433-463, Cambridge Planetary Science, Cambridge University Press, doi:10.1017/9781139060172.014. Bougher, S. W., K. J. Roeten, K. Olsen, P. R. Mahaffy, M. Benna, M. Elrod, S. K. Jain, N. M. Schneider, J. Deighan, E. Thiemann, F. G. Eparvier, A. Stiepen, and B. M. Jakosky (2017b), The structure and variability of Mars dayside thermosphere from MAVEN NGIMS and IUVS measurements: Seasonal and solar activity trends in scale heights and temperatures, Journal of Geophysical Research: Space Physics, 122(1), 1296-1313, doi:10.1002/2016JA023454.

Conrath, B. J. (1975), Thermal structure of the Martian atmosphere during the dissipation of the dust storm of 1971, Icarus, 24(1), 36-46.

Elrod, M. K., S. Bougher, J. Bell, P. R. Mahaffy, M. Benna, S. Stone, R. Yelle, and B. Jakosky (2017), He bulge revealed: $\mathrm{He}$ and $\mathrm{CO}_{2}$ diurnal and seasonal variations in the upper atmosphere of Mars as detected by MAVEN NGIMS, Journal of Geophysical Research: Space Physics, 122(2), 2564-2573, doi:10.1002/2016JA023482.

Elrod, M. K., S. M. Curry, E. M. B. Thiemann, and S. K. Jain (2018), September 2017 solar flare event: Rapid heating of the Martian neutral upper atmosphere from the X- 
class flare as observed by MAVEN, Geophysical Research Letters, 45(17), 8803-8810, doi:10.1029/2018GL077729.

England, S. L., G. Liu, E. Yig̈it, P. R. Mahaffy, M. Elrod, M. Benna, H. Nakagawa, N. Terada, and B. Jakosky (2016), MAVEN NGIMS observations of atmospheric gravity waves in the Martian thermosphere, Journal of Geophysical Research: Space Physics, 122(2), 2310-2335, doi:10.1002/2016JA023475.

Fang, X., S. W. Bougher, R. E. Johnson, Y. Ma, and M. W. Liemohn (2013), The importance of pickup oxygen ion precipitation to the Mars upper atmosphere under extreme solar wind conditions, Geophys. Res. Lett., 40, 1922-1927, doi:10.1002/grl.50415.

Forbes, J. M., F. G. Lemoine, S. L. Bruinsma, M. D. Smith, and X. Zhang (2008), Solar flux variability of Mars' exosphere densities and temperatures, Geophysical Research Letters, 35(1).

Forget, F., F. Montmessin, J.-L. Bertaux, F. González-Galindo, S. Lebonnois, E. Quermerais, A. Reberac, E. Dimarellis, and M. A. López-Valverde (2009), Density and temperatures of the upper Martian atmosphere measured by stellar occultations with Mars Express SPICAM, J. Geophys. Res., 114(E01004), doi:10.1029/2008JE003086.

Fox, J. L., and K. Y. Sung (2001), Solar activity variations of the Venus thermosphere/ionosphere, J. Geophys. Res., 106, 21,305-21,336, doi:10.1029/2001JA000069.

Fritts, D. C., L. Wang, and R. H. Tolson (2006), Mean and gravity wave structures and variability in the Mars upper atmosphere inferred from Mars Global Surveyor and Mars Odyssey aerobraking densities, Journal of Geophysical Research: Space Physics (19782012), 111(A12).

Gagné, M.-È., J.-L. Bertaux, F. González-Galindo, S. M. L. Melo, F. Montmessin, and K. Strong (2013), New nitric oxide (NO) nightglow measurements with SPICAM/MEx as a tracer of Mars upper atmosphere circulation and comparison with LMD-MGCM model prediction: Evidence for asymmetric hemispheres, Journal of Geophysical Research: Planets, 118(10), 2172-2179, doi:10.1002/jgre.20165.

González-Galindo, F., F. Forget, M. López-Valverde, M. Angelats i Coll, and E. Millour (2009), A ground-to-exosphere Martian general circulation model: 1. Seasonal, diurnal, and solar cycle variation of thermospheric temperatures, Journal of Geophysical Research: Planets, 114(E4), doi:10.1029/2008JE003246.

González-Galindo, F., S. W. Bougher, and M. A. López-Valverde (2010), Thermal and wind structure of the Martian thermosphere as given by two general circulation models, 
Planet. Space Sci., 58, 1832-1849, doi:10.1016/j.pss.2010.08.013.

González-Galindo, F., J.-Y. Chaufray, M. A. López-Valverde, G. Gilli, F. Forget,

F. Leblanc, R. Modolo, S. Hess, and M. Yagi (2013), 3D Martian Ionosphere model:

I. The photochemical ionosphere below $180 \mathrm{~km}$, Journal of Geophysical Research, 118, 2105-2123, doi:10.1002/jgre.20150.

Haberle, R. M., J. L. Hollingsworth, A. Colaprete, A. F. C. Bridger, C. P. McKay, J. R. Murphy, J. Schaeffer, and R. Freedman (2003), The NASA/AMES Mars General Circulation Model: Model improvements and comparison with observations, in Published Conference Abstract, International Workshop: Mars Atmosphere Modelling and Observations.

Heavens, N. G., M. I. Richardson, A. Kleinböhl, D. M. Kass, D. J. McCleese, W. Abdou, J. L. Benson, J. T. Schofield, J. H. Shirley, and P. M. Wolkenberg (2011), The vertical distribution of dust in the Martian atmosphere during northern spring and summer: Observations by the Mars Climate Sounder and analysis of zonal average vertical dust profiles, Journal of Geophysical Research: Planets, 116(E4), doi:10.1029/2010JE003691.

Jain, S. K., A. I. F. Stewart, N. M. Schneider, J. Deighan, A. Stiepen, J. S. Evans, M. H. Stevens, M. S. Chaffin, M. Crismani, W. E. McClintock, J. T. Clarke, G. M. Holsclaw, D. Y. Lo, F. Fefevre, F. Montmessin, E. M. B. Thiemann, F. Eparvier, and B. M. Jakosky (2015), The structure and variability of Mars upper atmosphere as seen in MAVEN/IUVS dayglow observations, Geophys. Res. Lett., 42, 9023-9030, doi: 10.1002/2015GL065419.

Jain, S. K., J. Deighan, N. M. Schneider, A. I. F. Stewart, J. S. Evans, E. M. B. Thiemann, M. S. Chaffin, M. Crismani, M. H. Stevens, M. K. Elrod, A. Stiepen, W. E. McClintock, D. Y. Lo, J. T. Clarke, F. G. Eparvier, F. Lefévre, F. Montmessin, G. M. Holsclaw, P. C. Chamberlin, and B. M. Jakosky (2018), Martian thermospheric response to an X8.2 solar flare on 10 September 2017 as seen by MAVEN/IUVS, Geophysical Research Letters, 45(15), 7312-7319, doi:10.1029/2018GL077731.

Jakosky, B. M., R. P. Lin, J. M. Grebowksy, J. G. Luhmann, and others (2015), The Mars Atmosphere and Volatile Evolution (MAVEN) Mission, Space Sci. Reviews, 195, 3-48, doi:doi:10.1007/s11214-015-0139-x.

Kass, D. M., A. Kleinöhl, D. J. McCleese, J. T. Schofield, and M. D. Smith (2016), Interannual similarity in the Martian atmosphere during the dust storm season, Geophysical Research Letters, 43(12), 6111-6118, doi:10.1002/2016GL068978. 
Keating, G. M, and E. J. Prior (1968), The winter helium bulge, Space Res., 8, 982-992. Keating, G., S. Bougher, M. Theriot, R. Tolson, R. Zurek, R. Blanchard, J. Murphy, and J.-L. Bertaux (2007), Mars neutral upper atmosphere temporal and spatial variations discovered from the accelerometer science experiment aboard Mars Reconnaissance Orbiter, in Lunar and Planetary Institute Science Conference Abstracts, vol. 38, p. 2074.

Keating, G. M., S. W. Bougher, R. W. Zurek, R. H. Tolson, G. J. Cancro, S. N. Noll, J. S. Parker, T. J. Schellenberg, R. W. Shane, B. L. Wilkerson, J. R. Murphy, J. L. Hollingsworth, R. M. Haberle, M. Joshi, J. C. Pearl, B. J. Conrath, M. D. Smith, R. T. Clancy, R. C. Blanchard, R. G. Wilmoth, D. F. Rault, T. Z. Martin, D. T. Lyons, P. B. Esposito, M. D. Johnston, C. W. Whetzel, C. G. Justus, and J. M. Babicke (1998), The structure of the upper atmosphere of Mars: In situ accelerometer measurements from Mars Global Surveyor, Science, 279, 1672-1676, doi:10.1126/science.279.5357.1672.

Kuroda, T., A. S. Medvedev, E. Yigit, and P. Hartogh (2015), A global view of gravity waves in the Martian atmosphere inferred from a high-resolution general circulation model, Geophysical Research Letters, 42(21), 9213-9222, doi:10.1002/2015GL066332.

Leblanc, F., J. Y. Chaufray, J. Lilensten, O. Witasse, and J.-L. Bertaux (2006), Martian dayglow as seen by the SPICAM UV spectrograph on Mars Express, Journal of Geophysical Research, 111(E09S11), doi:10.1029/2005JE002664.

Liu, X., W. Wang, J. P. Thayer, A. Burns, E. Sutton, S. C. Solomon, L. Qian, and G. Lucas (2014), The winter helium bulge revisited, Geophysical Research Letters, 41(19), 6603-6609, doi:10.1002/2014GL061471.

Mahaffy, P. R., M. Benna, M. Elrod, R. V. Yelle, S. W. Bougher, S. W. Stone, and B. M. Jakosky (2015a), Structure and composition of the neutral upper atmosphere of Mars from the MAVEN NGIMS investigation, Geophys. Res. Lett., 42, 8951-8957, doi: 10.1002/2015GL065329.

Mahaffy, P. R., M. Benna, T. King, D. N. Harpold, and R. e. a. Arvey (2015b), The Neutral Gas and Ion Mass Spectrometer on the Mars Atmosphere and Volatile Evolution Mission, Space Sci. Reviews, 195, 49-73, doi:doi:10.1007/s11214-014-0091-1.

McDunn, T. L., S. W. Bougher, J. Murphy, M. D. Smith, F. Forget, J.-L. Bertaux, and F. Montmessin (2010), Simulating the density and thermal structure of the middle atmosphere ( $80-130 \mathrm{~km}$ ) of Mars using the MGCM-MTGCM: A comparison with MEX/SPICAM observations, icarus, 206, 5-17, doi:10.1016/j.icarus.2009.06.034. 
Medvedev, A., and E. Yig̈it (2012), Thermal effects of internal gravity waves in the Martian upper atmosphere, Geophys. Res. Lett., 39, doi:10.1029/2012GL050852.

Medvedev, A., E. Yigit, P. Hartough, and E. Becker (2011a), Influence of gravity waves on the Martian atmosphere: General circulation modeling, J. Geophys. Res., 116, doi: 10.1029/2011JE003848.

Medvedev, A., F. González-Galindo, E. Yig̈it, A. G. Feofilov, F. Forget, and P. Hartogh (2015), Cooling of the Martian thermosphere by $\mathrm{CO}_{2}$ radiation and gravity waves: An intercomparison study with two general circulation models, J. Geophys. Res., 120, 913927, doi:10.1002/2015JE004802.

Medvedev, A. S., E. Yig̈it, and P. Hartogh (2011b), Estimates of gravity wave drag on Mars: Indication of a possible lower thermospheric wind reversal, Icarus, 211(1), 909 912, doi:https://doi.org/10.1016/j.icarus.2010.10.013.

Ridley, A., Y. Deng, and G. Tòth (2006), The Global Ionosphere-Thermosphere Model, J. Atmos. Sol-Terr. Phys., 68, 839.

Seidelmann, P. K., V. K. Abalakin, M. Bursa, M. E. Davies, C. de Bergh, J. H. Lieske, J. Oberst, J. L. Simon, E. M. Standish, P. Stooke, and et al. (2002), Report of the iau/iag working group on cartographic coordinates and rotational elements of the planets and satellites: 2000, Celestial Mechanics and Dynamical Astronomy, 82(1), 83âĂŞ111, doi:10.1023/A:1013939327465.

Smith, M. D. (2009), THEMIS observations of Mars aerosol optical depth from 20022008, icarus, 202, 444-452, doi:10.1016/j.icarus.2009.03.027.

Stewart, A. I. (1972), Mariner 6 and 7 ultraviolet spectrometer experiment: Implications for $\mathrm{CO}_{2}+, \mathrm{CO}$ and $\mathrm{O}$ airglow, Journal of Geophysical Research, 77, 1.

Stewart, A. I., C. Barth, C. Hord, and A. Lane (1972), Mariner 9 ultraviolet spectrometer experiment: Structure of Mars' upper atmosphere, Icarus, 17(2), 469-474.

Stiepen, A., S. K. Jain, N. M. Schneider, J. I. Deighan, F. González-Galindo, J.-C. Gérard, Z. Milby, M. H. Stevens, S. Bougher, J. S. Evans, A. I. F. Stewart, M. S. Chaffin, M. Crismani, W. E. McClintock, J. T. Clarke, G. M. Holsclaw, F. Montmessin, F. Lefèvre, F. Forget, D. Y. Lo, B. Hubert, and B. M. Jakosky (2017), Nitric oxide nightglow and Martian mesospheric circulation from MAVEN/IUVS observations and LMD-MGCM predictions, Journal of Geophysical Research: Space Physics, 122(5), 5782-5797, doi:10.1002/2016JA023523. 
Thiemann, E. M. B., P. C. Chamberlin, F. G. Eparvier, B. Templeman, T. N. Woods, S. W. Bougher, and B. M. Jakosky (2017), The MAVEN EUVM model of solar spectral irradiance variability at Mars: Algorithms and results, Journal of Geophysical Research: Space Physics, 122(3), 2748-2767, doi:10.1002/2016JA023512.

Tolson, R., A. Dwyer, J. Hanna, G. Keating, B. George, P. Escalera, and M. Werner (2005), Application of accelerometer data to Mars Odyssey aerobraking and atmospheric modeling, Journal of Spacecraft and Rockets, 42(3), 435-443.

Winchester, C., and D. Rees (1995), Numerical models of the Martian coupled thermosphere and ionosphere, Advances in Space Research,15(4), 51-68, doi:10.1016/02731177(94)00064-8.

Yig̈it, E., S. L. England, G. Liu, A. S. Medvedev, P. R. Mahaffy, T. Kuroda, and B. M. Jakosky (2015), High-altitude gravity waves in the Martian thermosphere observed by MAVEN/NGIMS and modeled by a gravity wave scheme, Geophysical Research Letters, 42(21), 8993-9000, doi:10.1002/2015GL065307.

Zurek, R. W., R. A. Tolson, S. W. Bougher, R. A. Lugo, D. T. Baird, J. M. Bell, and B. M. Jakosky (2017), Mars thermosphere as seen in MAVEN accelerometer data, Journal of Geophysical Research: Space Physics, 122(3), 3798-3814, doi: 10.1002/2016JA023641. 
Table 1. Geophysical characteristics of the five selected NGIMS wind campaigns

\begin{tabular}{ccccc}
\hline Orbits & Campaign Dates & Ls $^{a}$ (degrees) & Local Time (hour) & Latitude (degrees) \\
\hline $3861-3865$ & September 22-23, 2016 & $227-229$ & $18.1-19.6$ & $-26--60$ \\
$4437-4446$ & January 11-13, 2017 & $297-299$ & $23.4-1.2$ & $-38--66$ \\
$5170-5179$ & May 30- June 1, 2017 & $12-13$ & $9.7-11.5$ & $30-61$ \\
$6198-6202$ & December 7-8, 2017 & $97-98$ & $8.8-9.5$ & $-3--32$ \\
$6532-6541$ & February 7-9, 2018 & $126-127$ & $0.0-3.5$ & $-73--50$ \\
\hline
\end{tabular}

${ }^{a}$ Solar longitude

Table 2. Campaign averaged speeds $(\mathrm{m} / \mathrm{s})$

\begin{tabular}{|c|c|c|c|c|c|c|}
\hline Campaign & $\begin{array}{l}\text { NGIMS } \\
\text { Average }^{a}\end{array}$ & Range $^{b}$ & $1-\sigma$ Speed $^{c}$ & $\begin{array}{l}\text { M-GITM } \\
\text { Average }^{a}\end{array}$ & Range $^{b}$ & $1-\sigma$ Speed $^{c}$ \\
\hline September 2016 & 317 & $262-357$ & 55 & 161 & $103-200$ & 12 \\
\hline January 2017 & 56 & $32-79$ & 39 & 263 & $237-293$ & 3 \\
\hline May 2017 & 117 & $61-149$ & 39 & 154 & $136-177$ & 2 \\
\hline December 2017 & 202 & $178-230$ & 26 & 157 & $145-171$ & 2 \\
\hline February 2018 & 221 & $200-247$ & 80 & 129 & $116-146$ & 2 \\
\hline
\end{tabular}

${ }^{a}$ This average is both the campaign average and the average over all altitudes.

${ }^{b}$ The range of speeds seen in the campaign averaged altitude profile.

${ }^{c}$ The standard deviation of speed averaged over all altitudes. 
Table 3. Campaign averaged direction (degrees from North)

\begin{tabular}{l|ccc|ccc}
\hline & $\begin{array}{c}\text { NGIMS } \\
\text { Campaign }\end{array}$ & Average $^{a}$ & Range $^{b}$ & $1^{\text {M-GITM }}$ & & \\
September 2016 & 17 & $-7-27$ & 5 & 27 & $14-42$ & 1 \\
January 2017 & 188 & $161-230$ & 67 & 289 & $281-300$ & 4 \\
May 2017 & 137 & $97-164$ & 37 & 320 & $308-329$ & 3 \\
December 2017 & 298 & $275-328$ & 21 & 240 & $220-257$ & 1 \\
February 2018 & 2 & $-19-27$ & 27 & -34 & $-39--28$ & 3 \\
\hline
\end{tabular}

${ }^{a}$ This average is both the campaign average and the average over all altitudes.

${ }^{b}$ The range of directions seen in the campaign averaged altitude profile.

${ }^{c}$ The standard deviation of direction averaged over all altitudes.

Table 4. Coefficient of Variation values for the selected campaigns

\begin{tabular}{lcc}
\hline Campaign & Range & Average \\
\hline September 2016 & $0.08-0.31$ & 0.17 \\
January 2017 & $0.72-1.92$ & 1.26 \\
May 2017 & $0.32-1.33$ & 0.80 \\
December 2017 & $0.08-0.73$ & 0.28 \\
February 2018 & $0.37-1.07$ & 0.52 \\
\hline
\end{tabular}




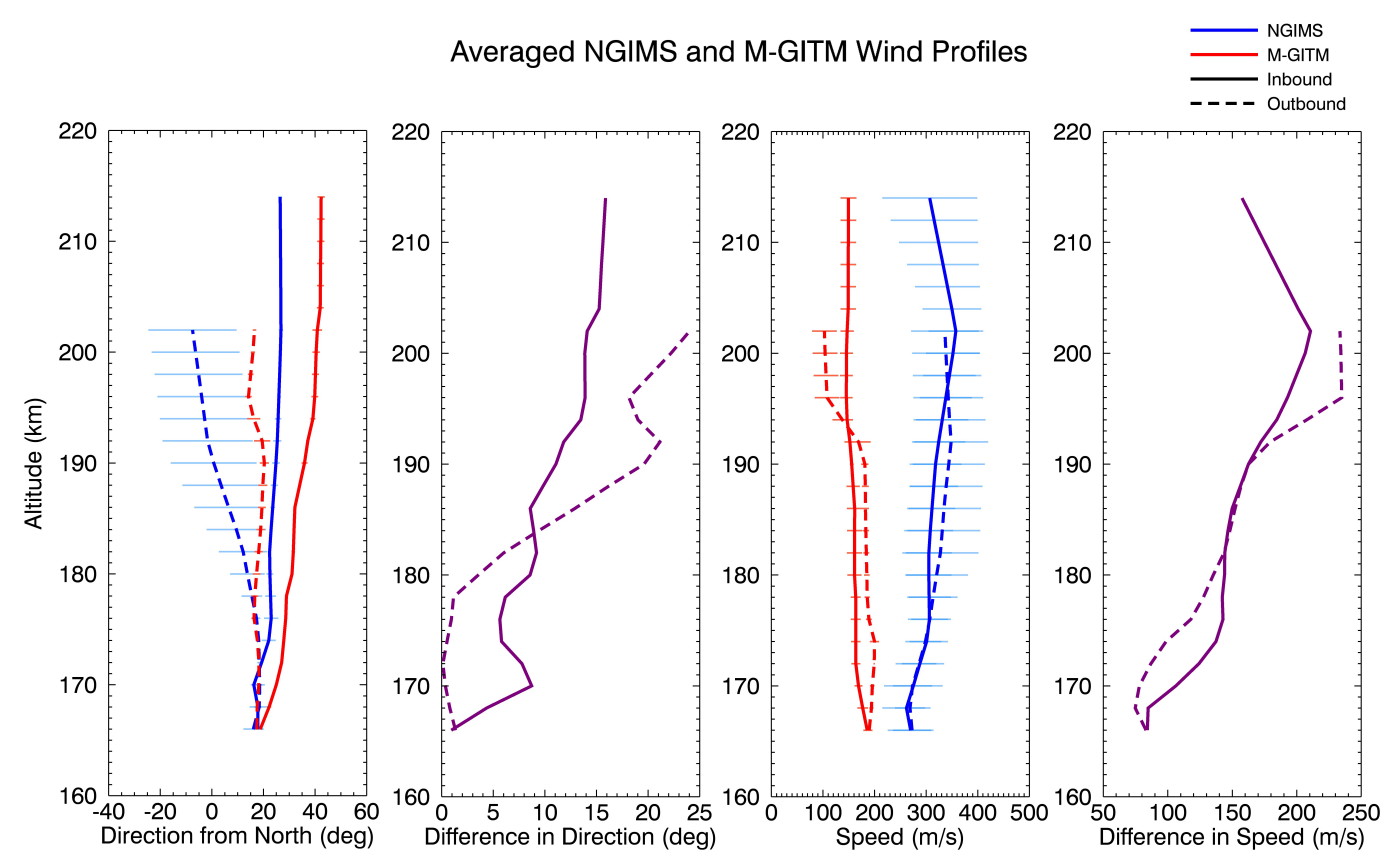

Figure 1. Averaged NGIMS (blue) and M-GITM (red) altitude profiles of wind speed and direction for the September 2016 campaign. The purple profiles show the differences in speed and direction between NGIMS and M-GITM campaign averages. The solid lines show the inbound segment of the orbit while the dashed lines indicate the outbound segment. Horizontal lines show one standard deviation of orbit-to-orbit variability over the campaign. Note that direction is plotted in degrees from North (in a clockwise sense). 


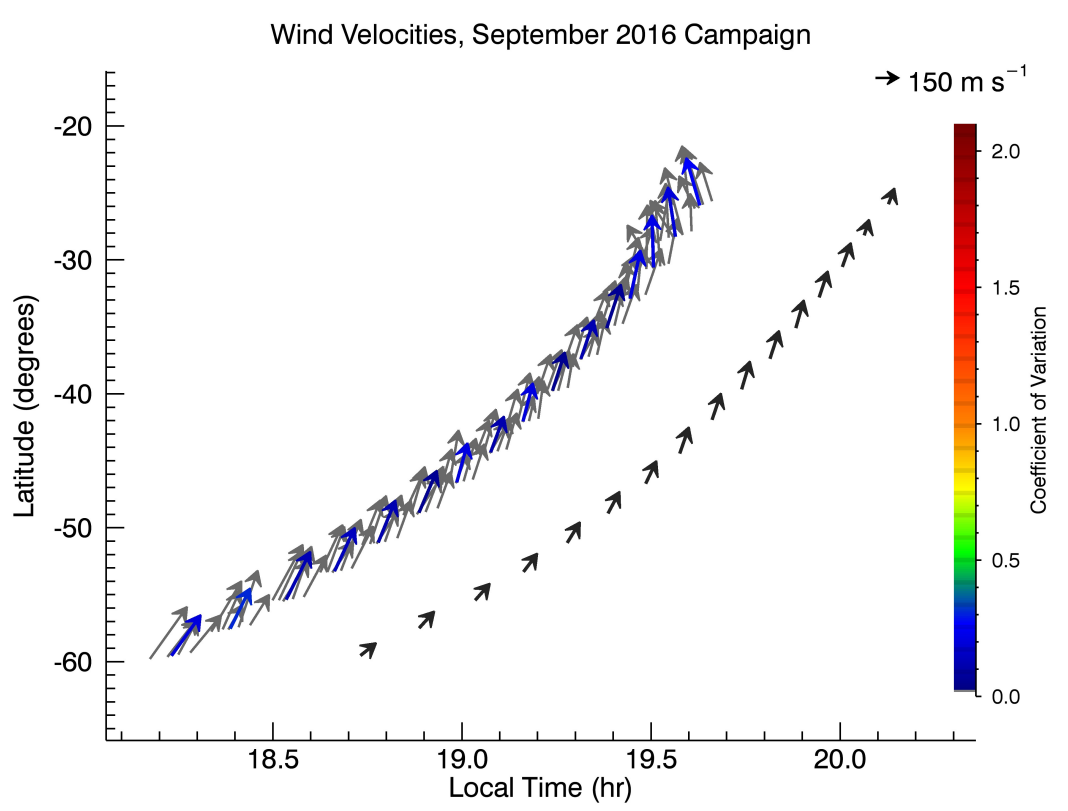

Figure 2. Wind vectors from the September 2016 NGIMS observational campaign in latitude and local time. Gray vectors show all observations from each individual orbit of the campaign while the colored vectors represent the campaign averaged velocities. The colors of the campaign averaged vectors represent the calculated coefficient of variation along the track, with higher values indicating more orbit-to-orbit variability. Note that these plots from all campaigns use the same color scale for the coefficient of variation. The black vectors show the averaged M-GITM simulated velocities. The M-GITM vectors have been set to one half hour later in local time than the NGIMS observations for readability on these plots. Individual orbits of M-GITM flythroughs are not shown since the vectors stack on top of each other due to minimal orbit-to-orbit variability simulated by the model. 


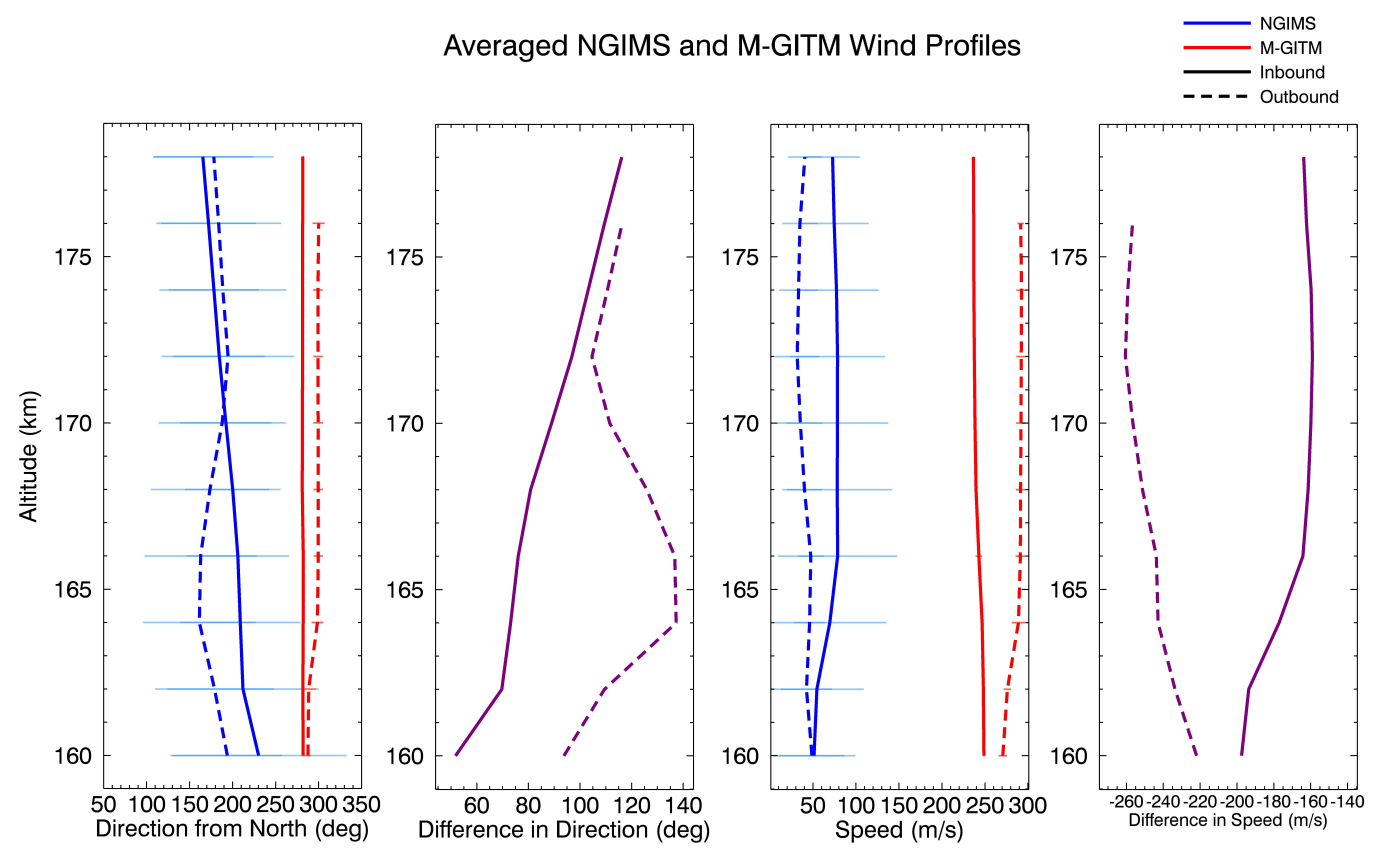

Figure 3. Averaged altitude profiles of wind speed and direction from the January 2017 campaign and corresponding model flythrough, with $1-\sigma$ orbit-to-orbit variability. Plots are in the same format as those in Figure 1.

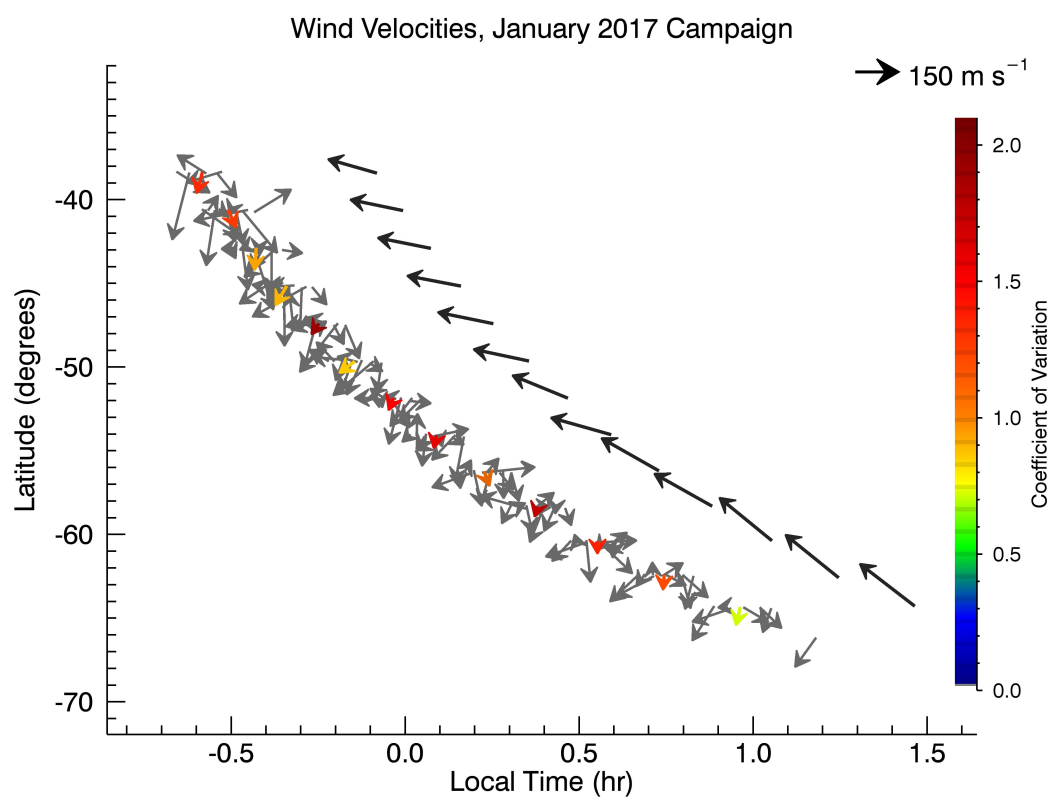

Figure 4. Averaged (colored) and individual (gray) wind velocity vectors from the January 2017 campaign. Black vectors show averaged simulated wind velocities from M-GITM, shifted from the NGIMS observations by half an hour in local time. The plot is in the same format as that in Figure 2. 

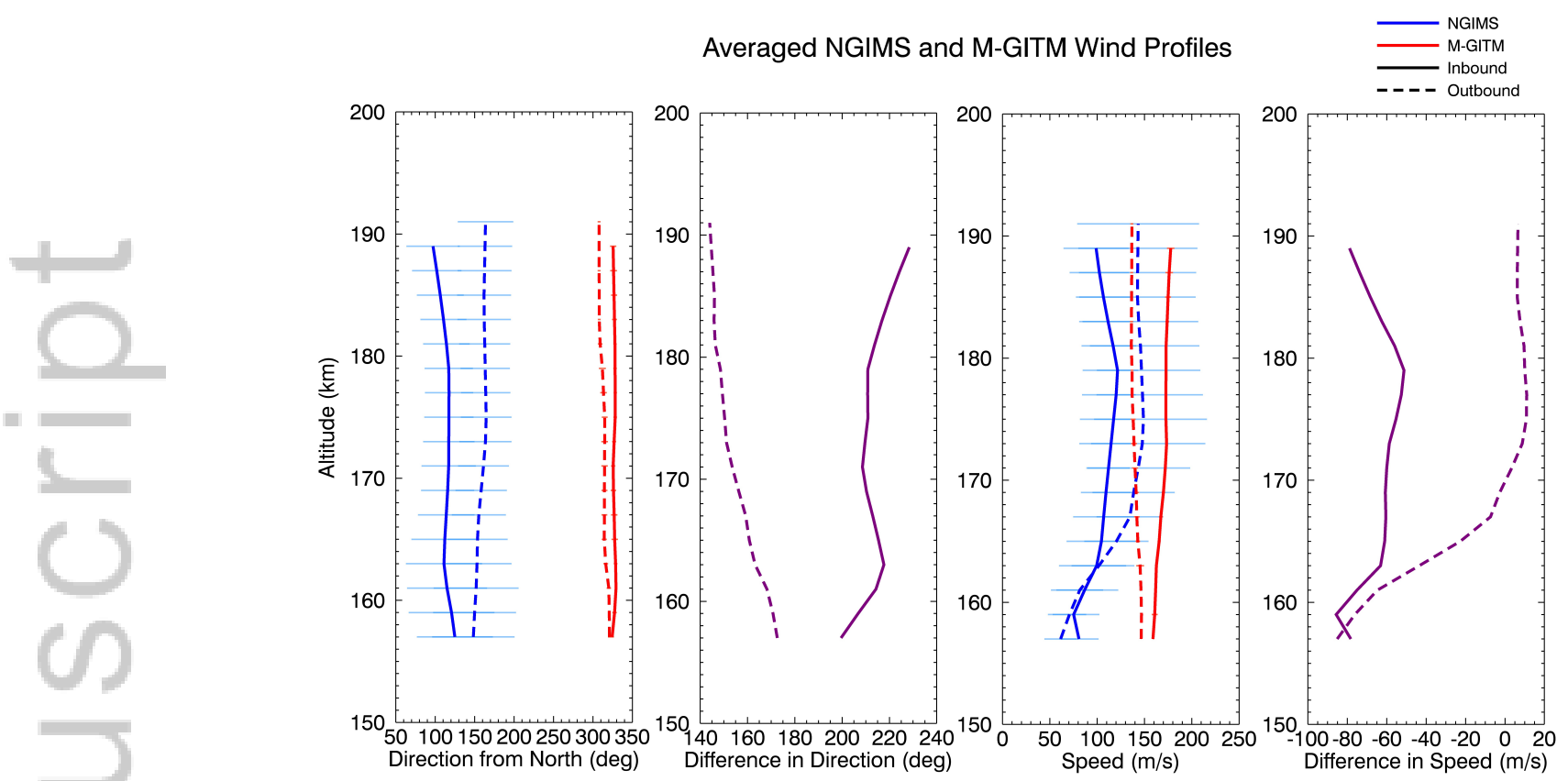

Figure 5. Averaged altitude profiles of wind speed and direction from the May 2017 campaign and corresponding model flythrough, with 1- $\sigma$ orbit-to-orbit variability. Plots are in the same format as those in Figure 1.

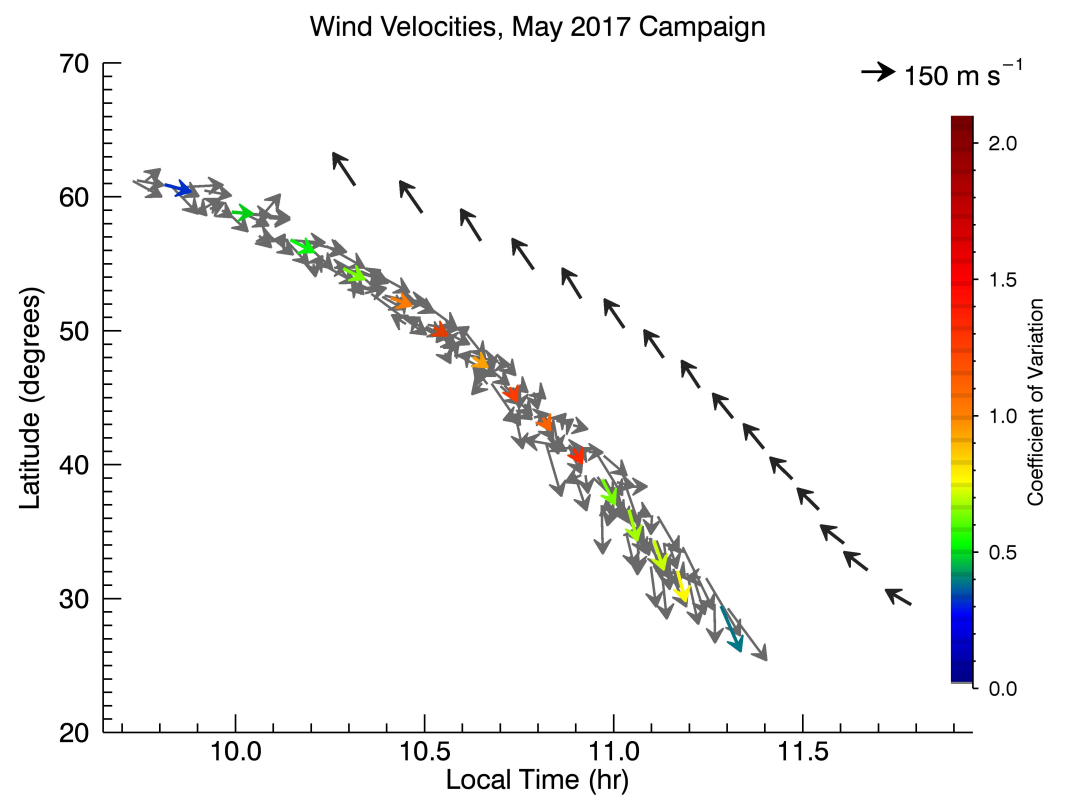

Figure 6. Averaged (colored) and individual (gray) wind velocity vectors from the May 2017 campaign.

Black vectors show averaged simulated wind velocities from M-GITM, shifted from the NGIMS observations by half an hour in local time. The plot is in the same format as that in Figure 2. 


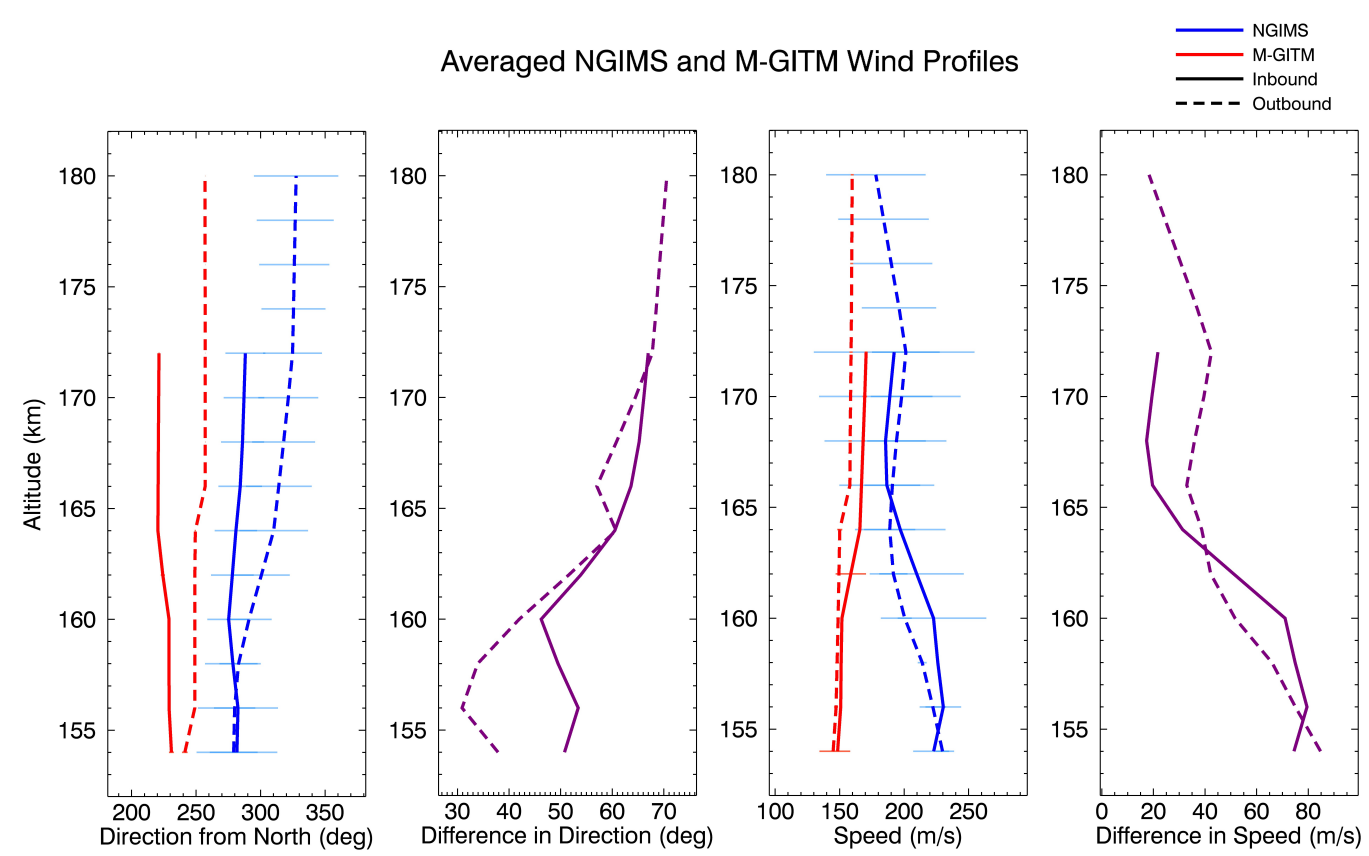

Figure 7. Averaged altitude profiles of wind speed and direction from the December 2017 campaign and corresponding model flythrough, with 1- $\sigma$ orbit-to-orbit variability. Plots are in the same format as those in Figure 1.

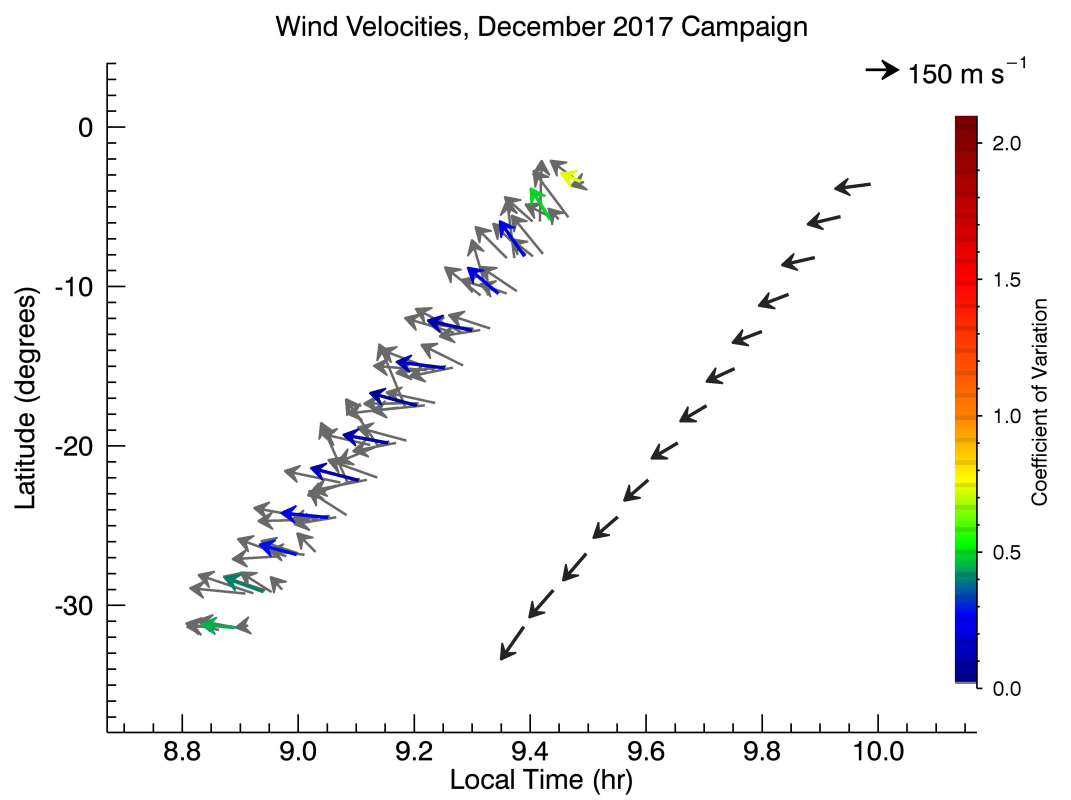

Figure 8. Averaged (colored) and individual (gray) wind velocity vectors from the December 2017 campaign. Black vectors show averaged simulated wind velocities from M-GITM, shifted from the NGIMS observations by half an hour in local time. The plot is in the same format as that in Figure 2. 


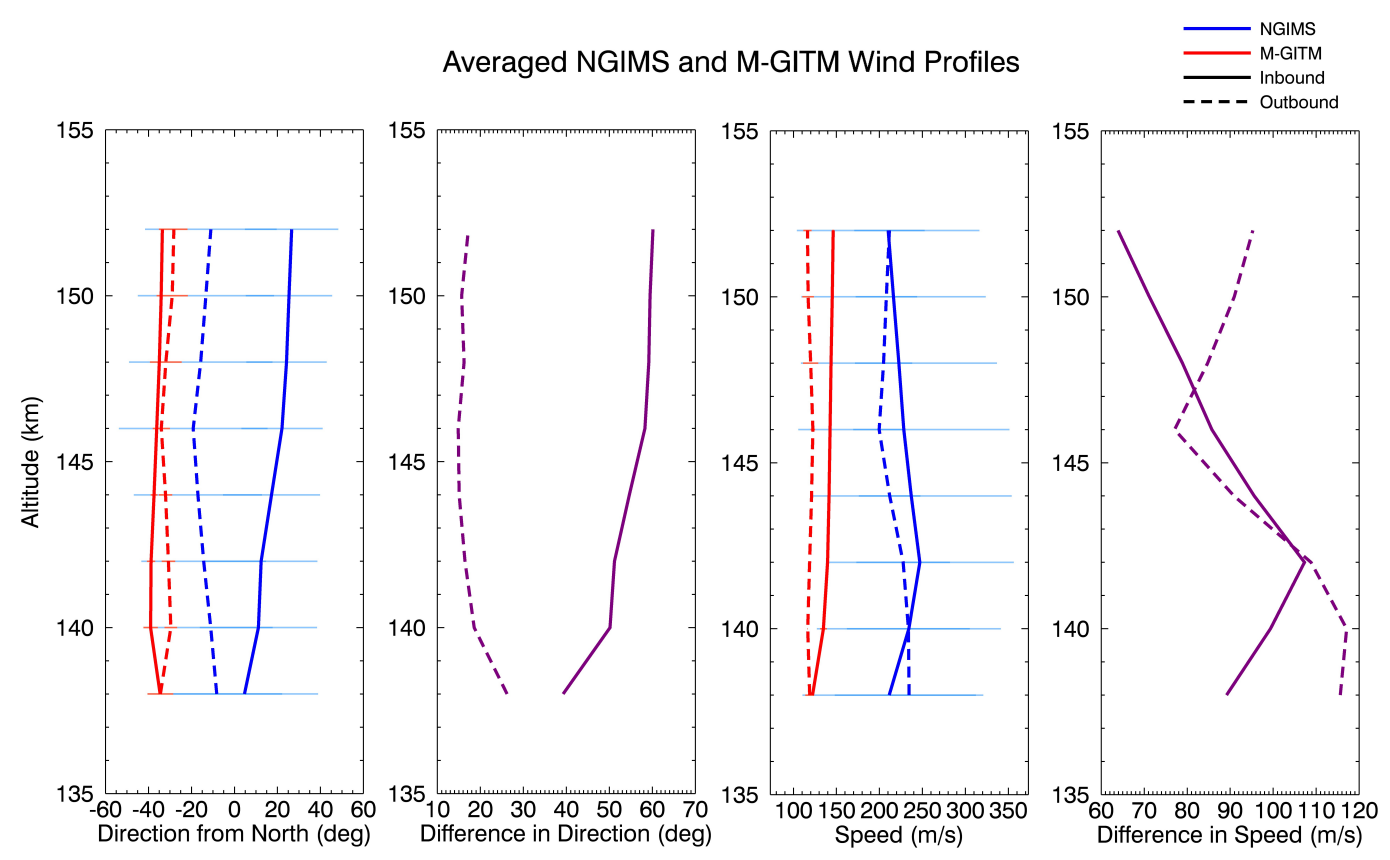

Figure 9. Averaged altitude profiles of wind speed and direction from the February 2018 campaign and corresponding model flythrough, with 1- $\sigma$ orbit-to-orbit variability. Plots are in the same format as those in Figure 1.

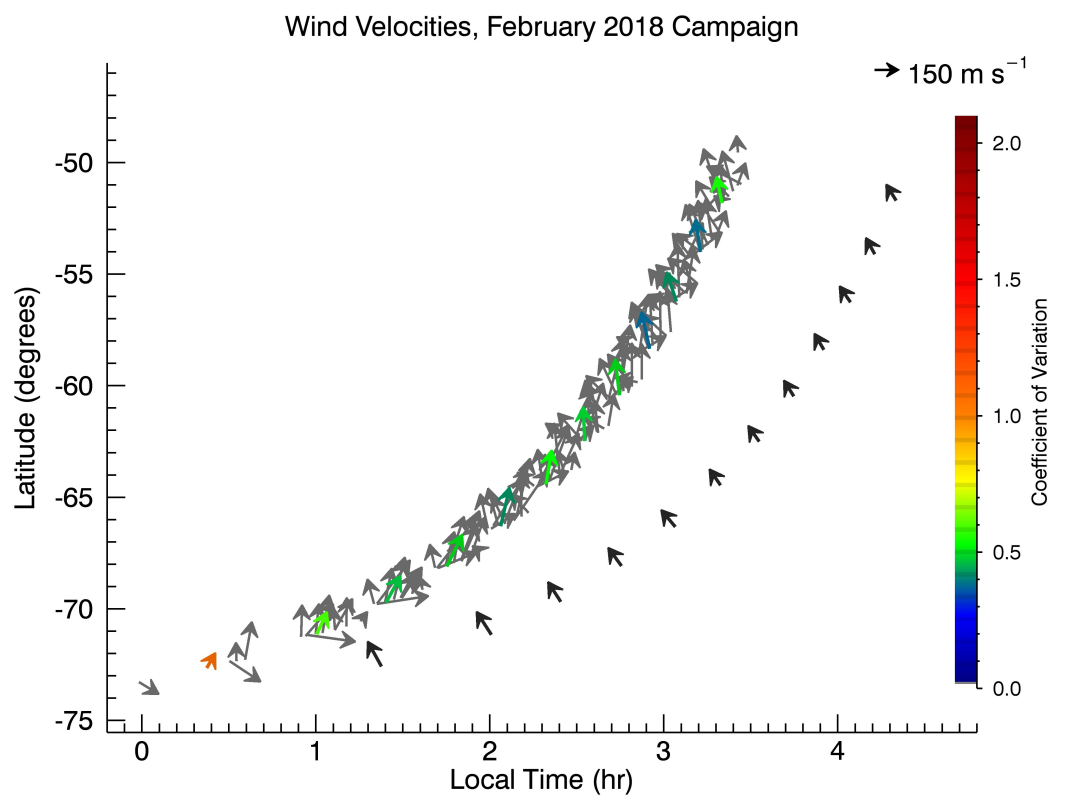

Figure 10. Averaged (colored) and individual (gray) wind velocity vectors from the February 2018 campaign. Black vectors show averaged simulated wind velocities from M-GITM, shifted from the NGIMS observations by an hour in local time. The plot is in the same format as that in Figure 2. 


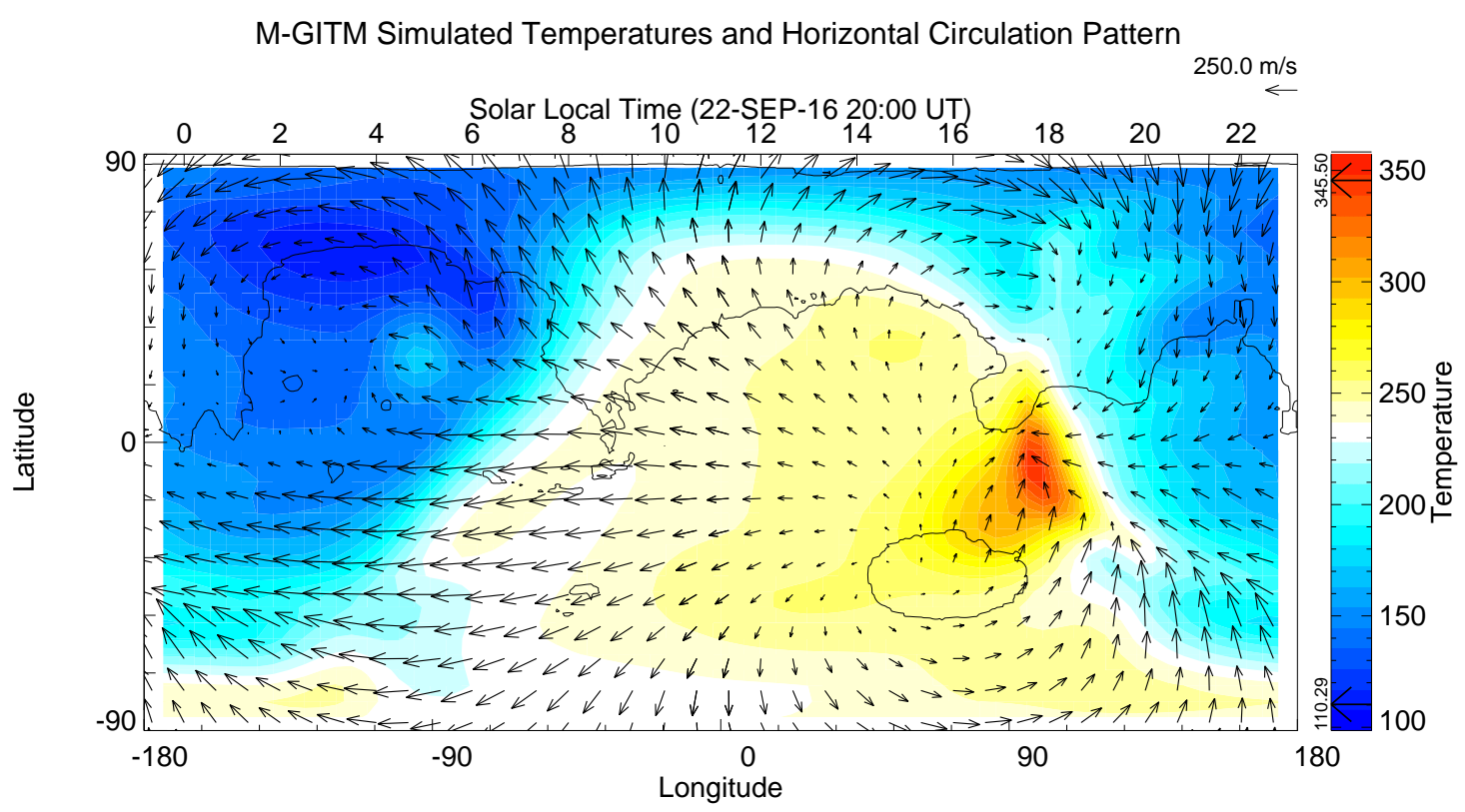

Figure 11. M-GITM simulation of September 22, 2016, showing temperatures (K) and wind velocity vectors at $170 \mathrm{~km}$. 


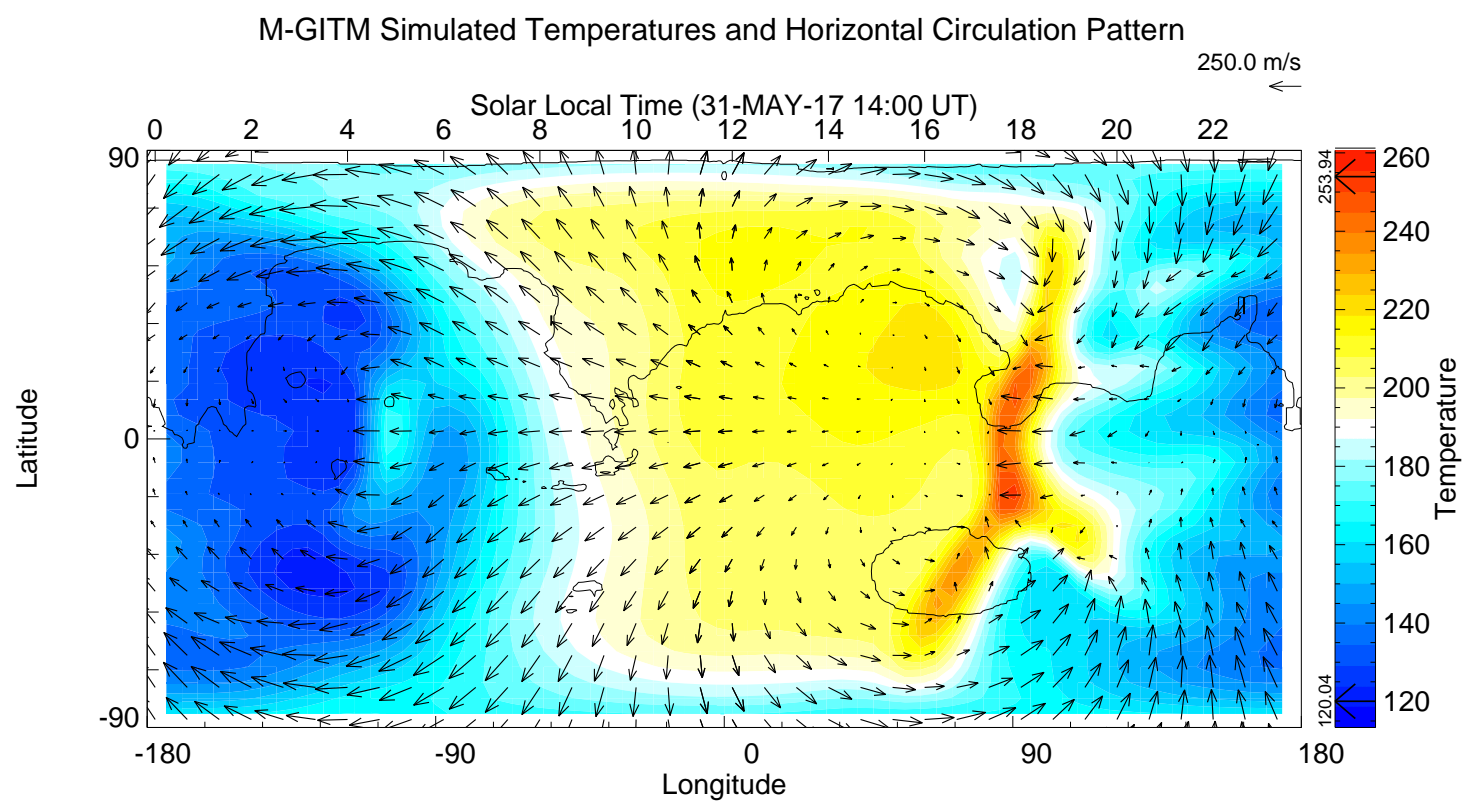

Figure 12. M-GITM simulation of May 31,2017 , showing temperatures $(K)$ and wind velocity vectors at $170 \mathrm{~km}$. 


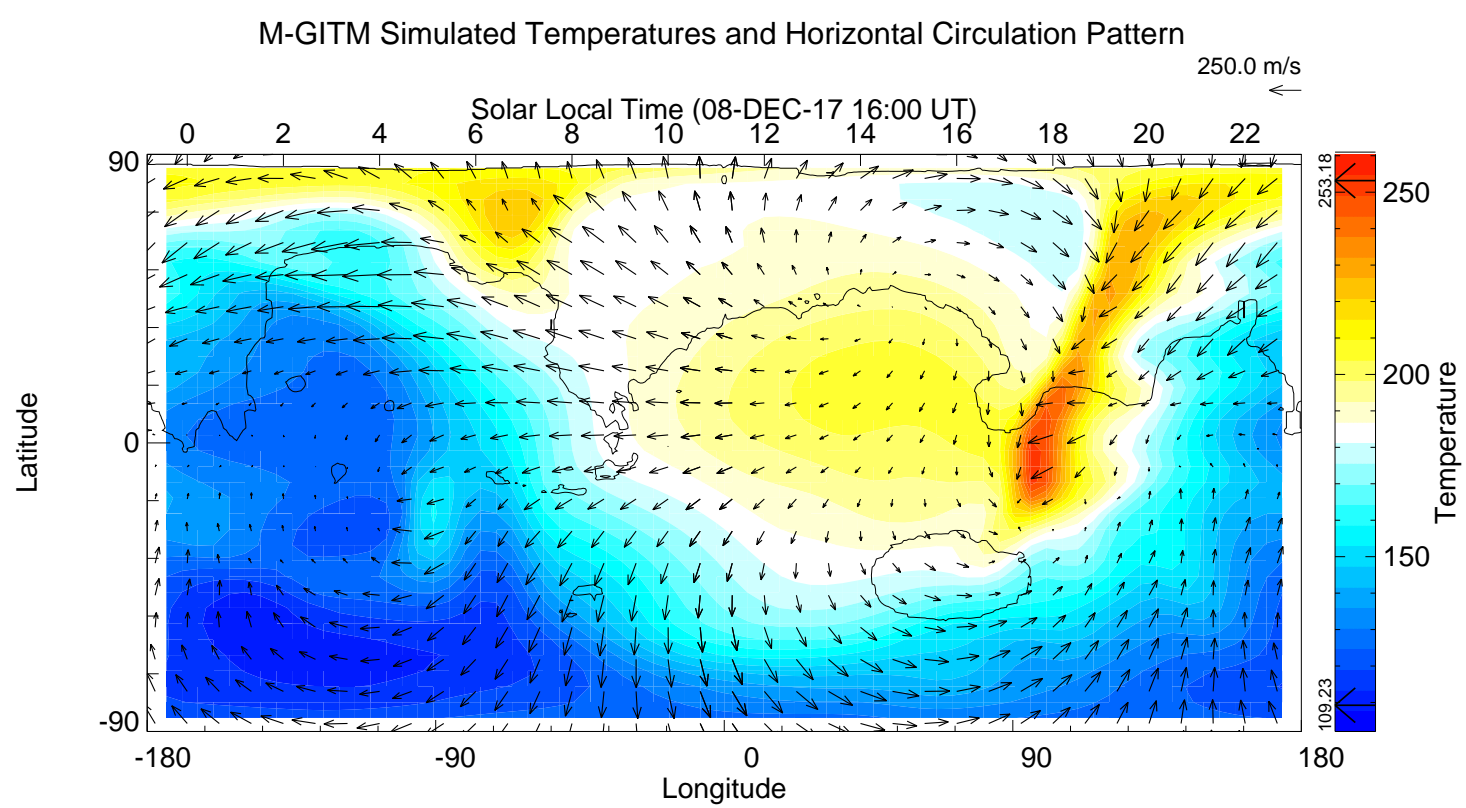

Figure 13. M-GITM simulation of December 8, 2017, showing temperatures $(\mathrm{K})$ and wind velocity vectors at $170 \mathrm{~km}$. 
Averaged NGIMS and M-GITM Wind Profiles

Figure 2.
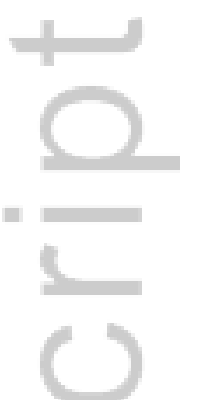

$\infty$
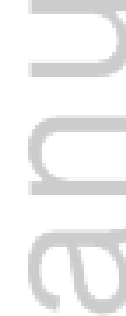

This article is protected by copyright. All rights reserved. 
Wind Velocities, September 2016 Campaign

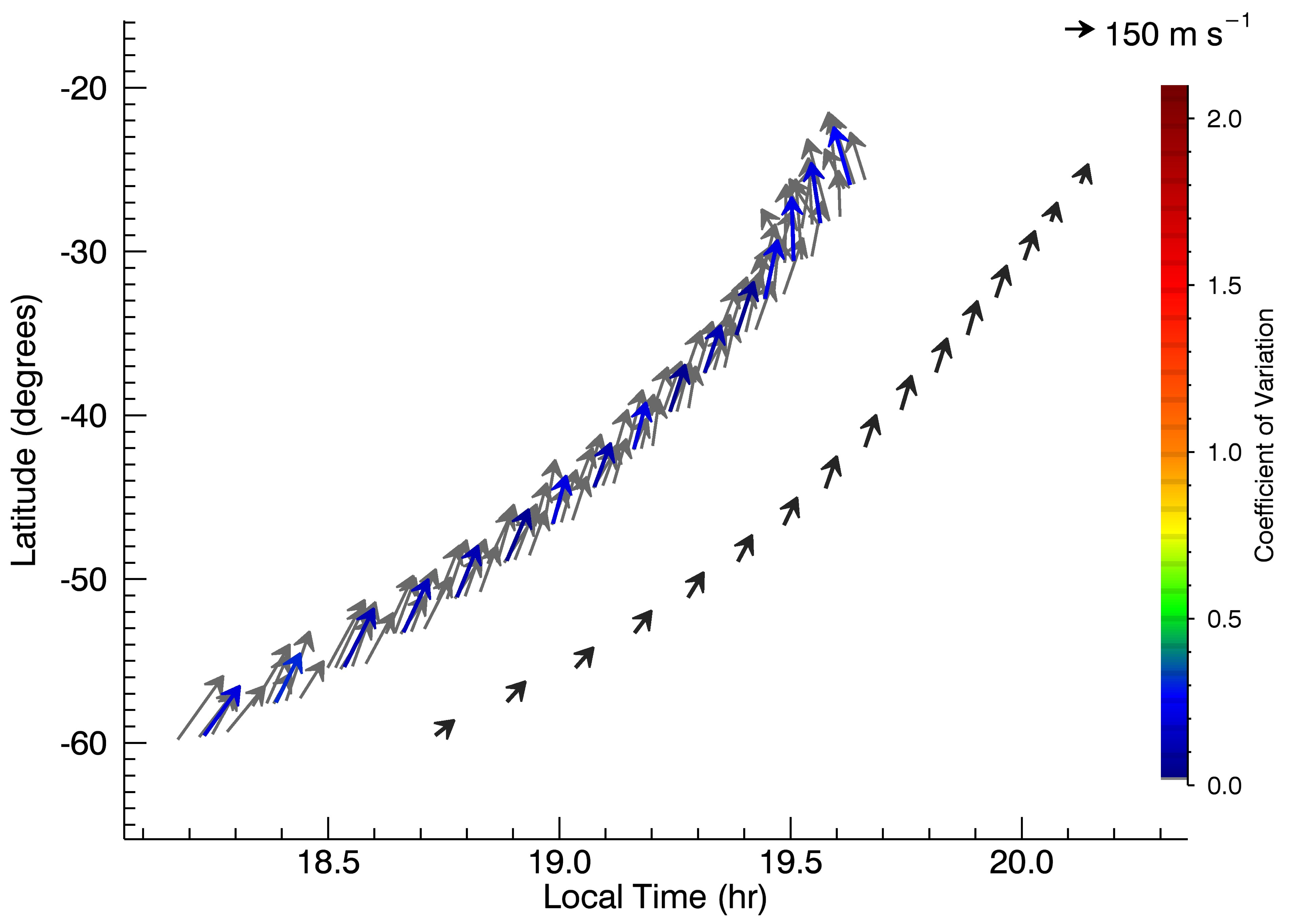




\section{Averaged NGIMS and M-GITM Wind Profiles}

Wind Velocities, January 2017 Campaign

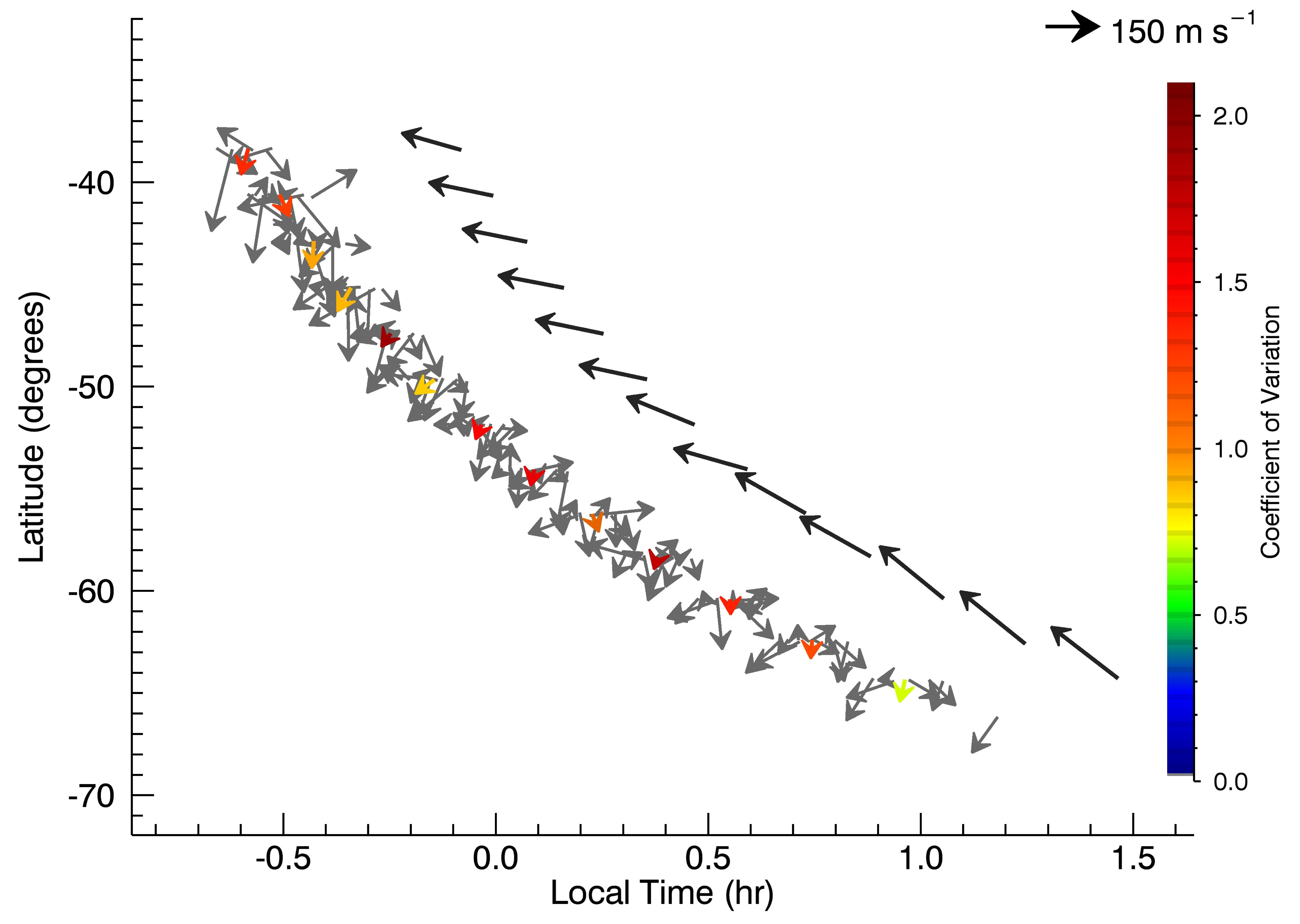


Figure 5.
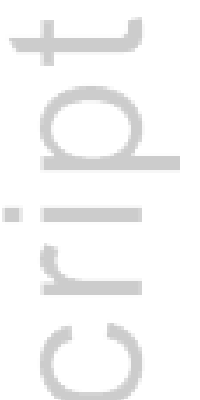

$\infty$
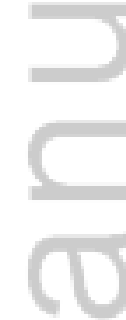

This article is protected by copyright. All rights reserved. 


\section{Averaged NGIMS and M-GITM Wind Profiles}

Wind Velocities, May 2017 Campaign

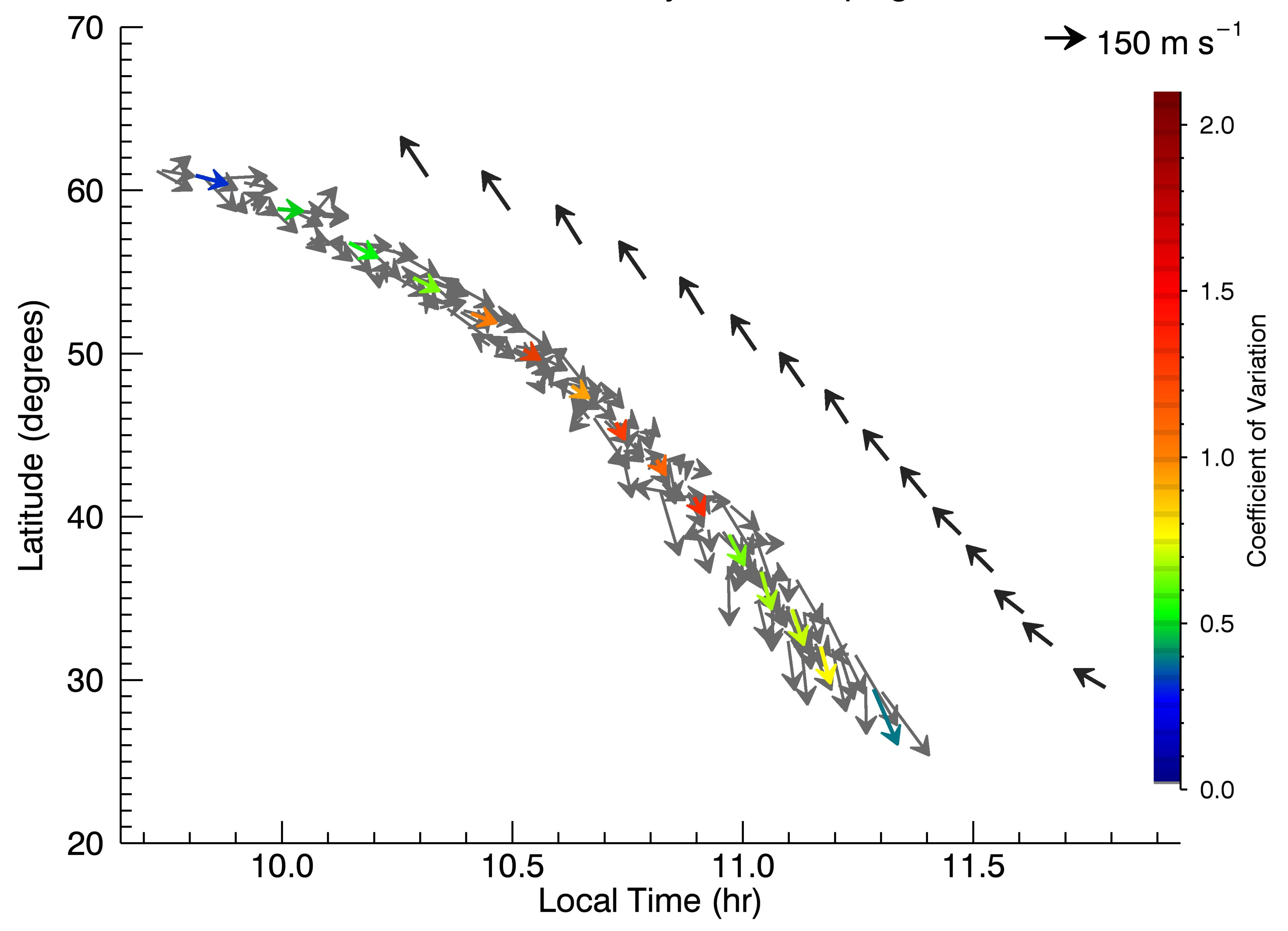




\section{Averaged NGIMS and M-GITM Wind Profiles}

Wind Velocities, December 2017 Campaign

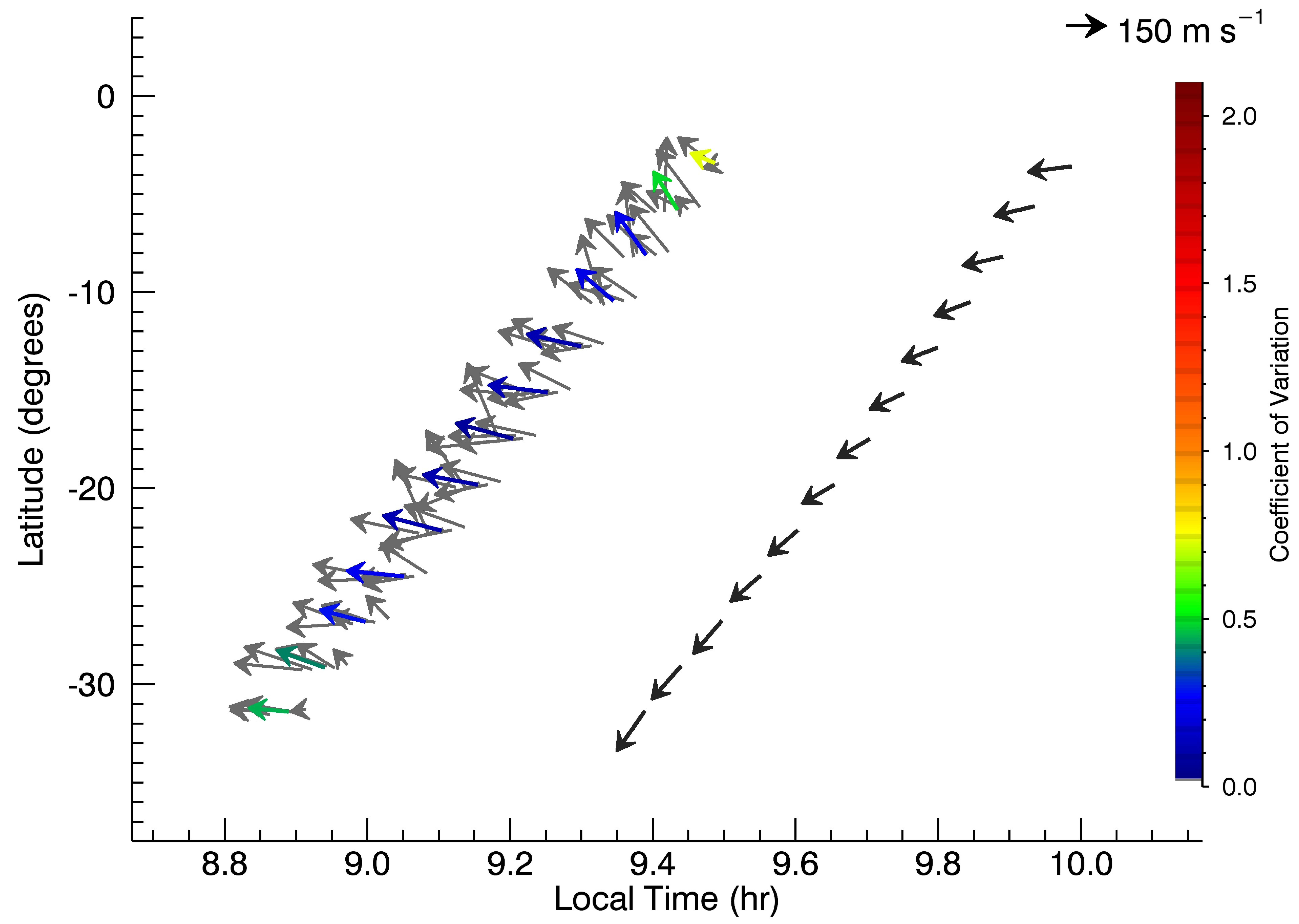


Figure 9.
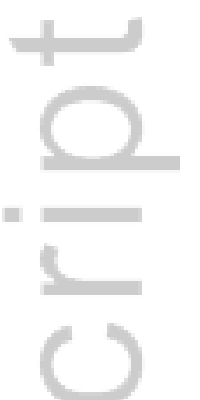

$\infty$
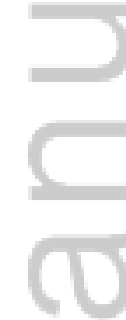

This article is protected by copyright. All rights reserved. 


\section{Averaged NGIMS and M-GITM Wind Profiles}

Wind Velocities, February 2018 Campaign

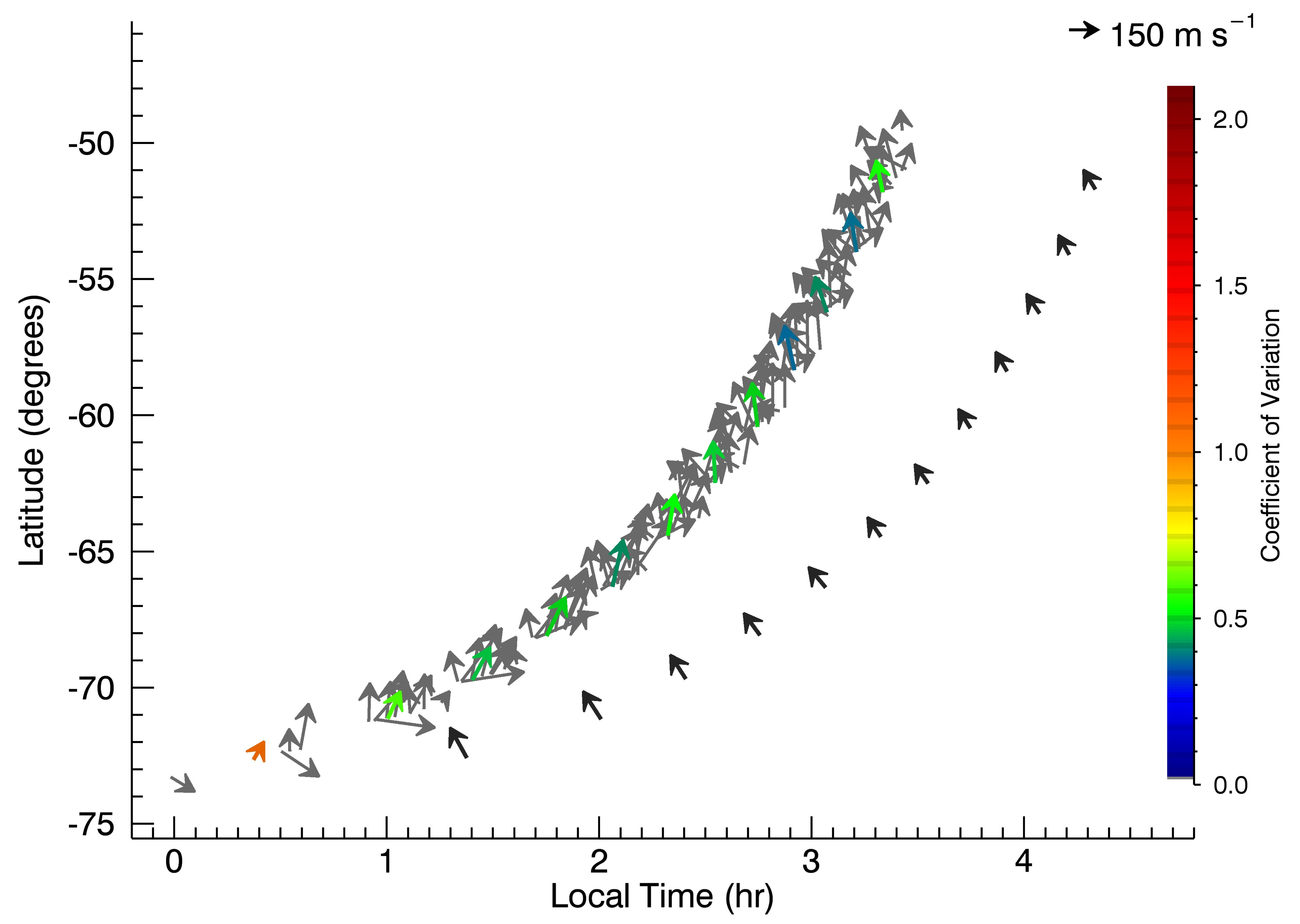




\section{M-GITM Simulated Temperatures and Horizontal Circulation Pattern}

$250.0 \mathrm{~m} / \mathrm{s}$

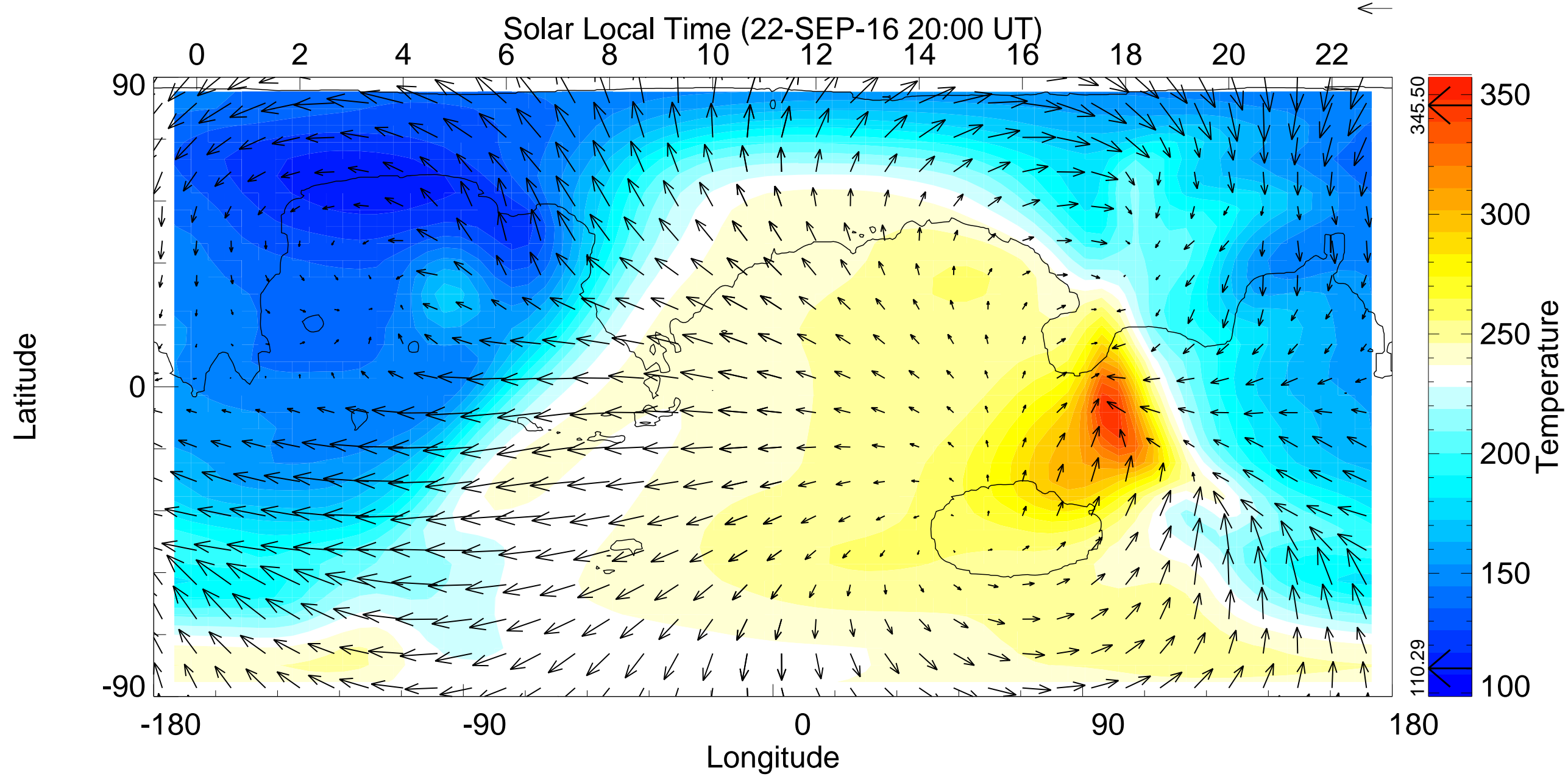

This article is protected by copyright. All rights reserved. 
Figure 12.
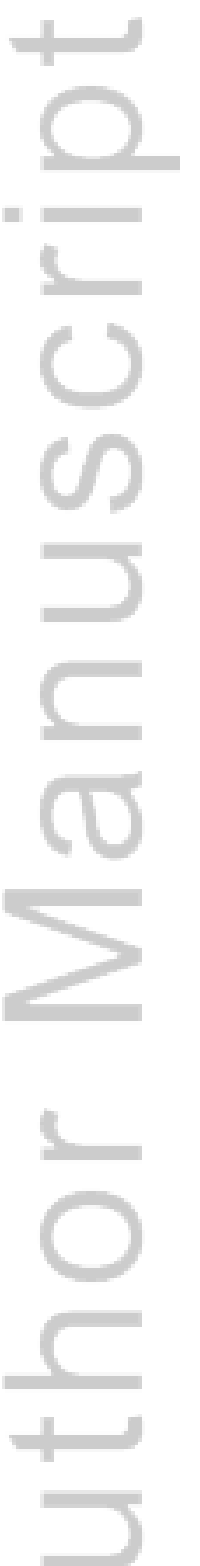

This article is protected by copyright. All rights reserved. 


\section{M-GITM Simulated Temperatures and Horizontal Circulation Pattern}

$250.0 \mathrm{~m} / \mathrm{s}$

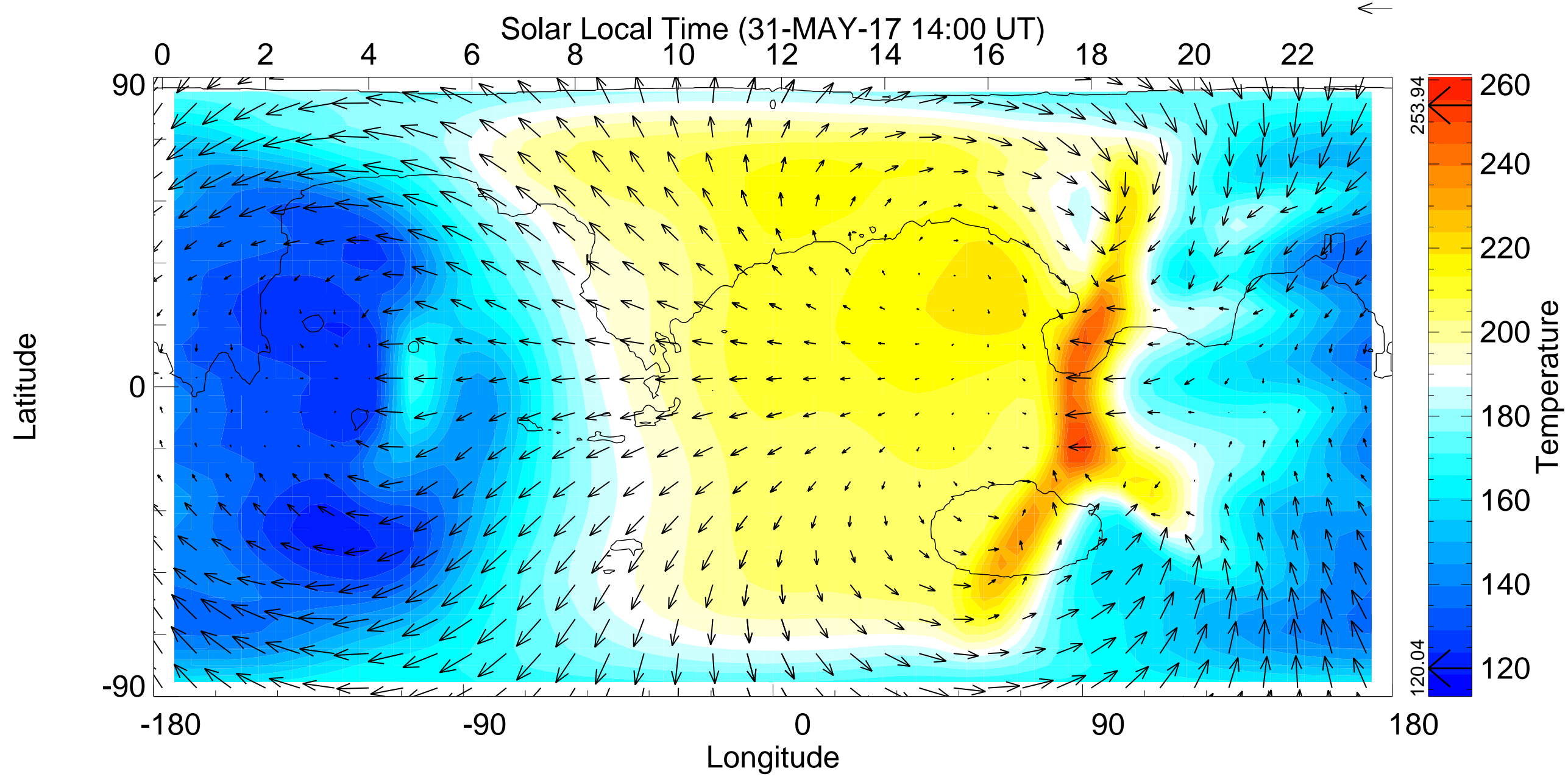

This article is protected by copyright. All rights reserved. 


\section{M-GITM Simulated Temperatures and Horizontal Circulation Pattern}

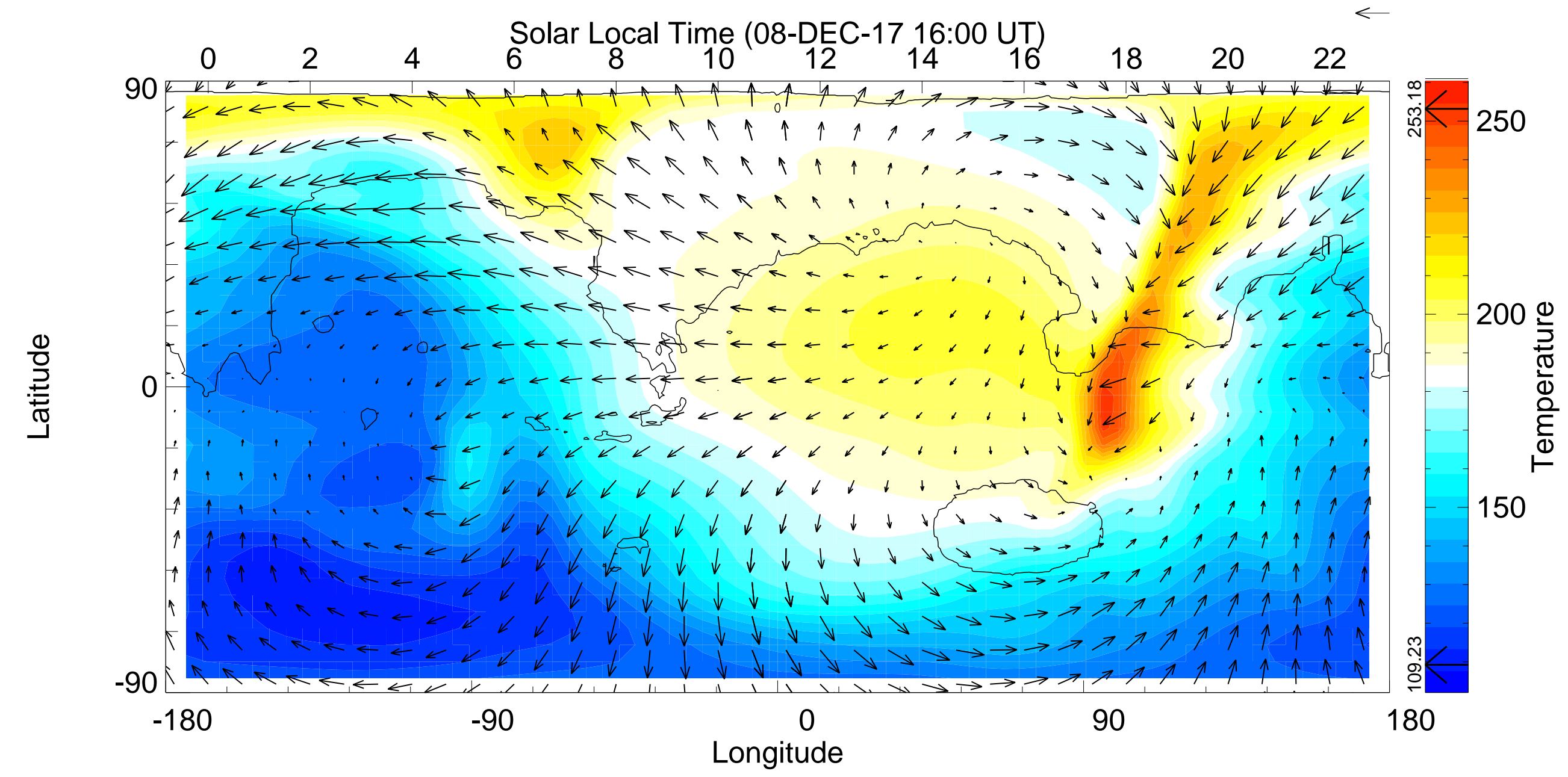

This article is protected by copyright. All rights reserved. 


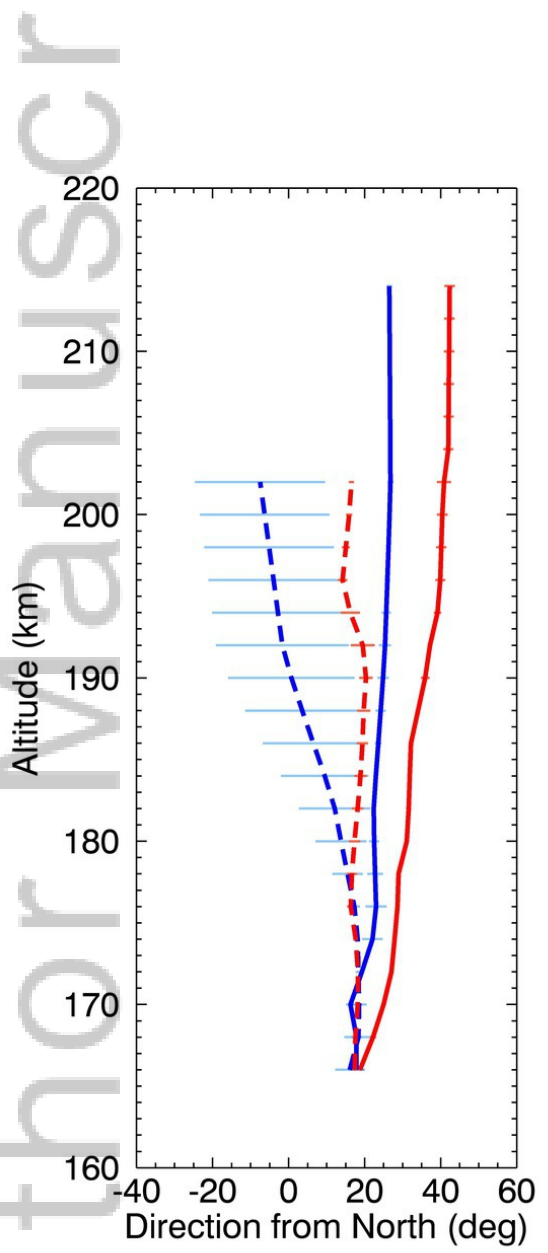

Averaged NGIMS and M-GITM Wind Profiles

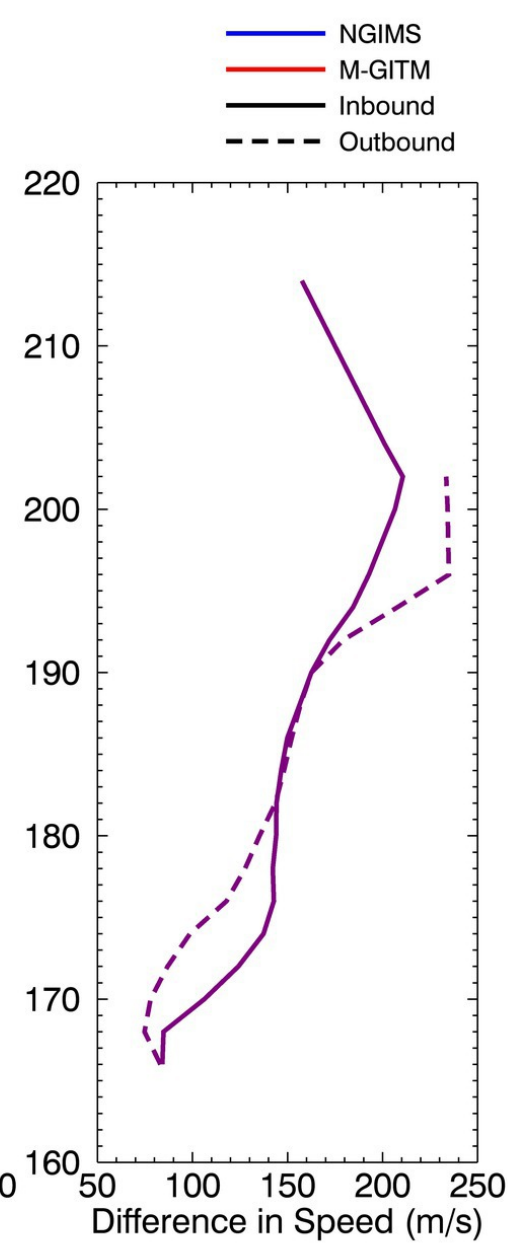

2019JE005957-f01-z-.jpg

This article is protected by copyright. All rights reserved. 
Wind Velocities, September 2016 Campaign

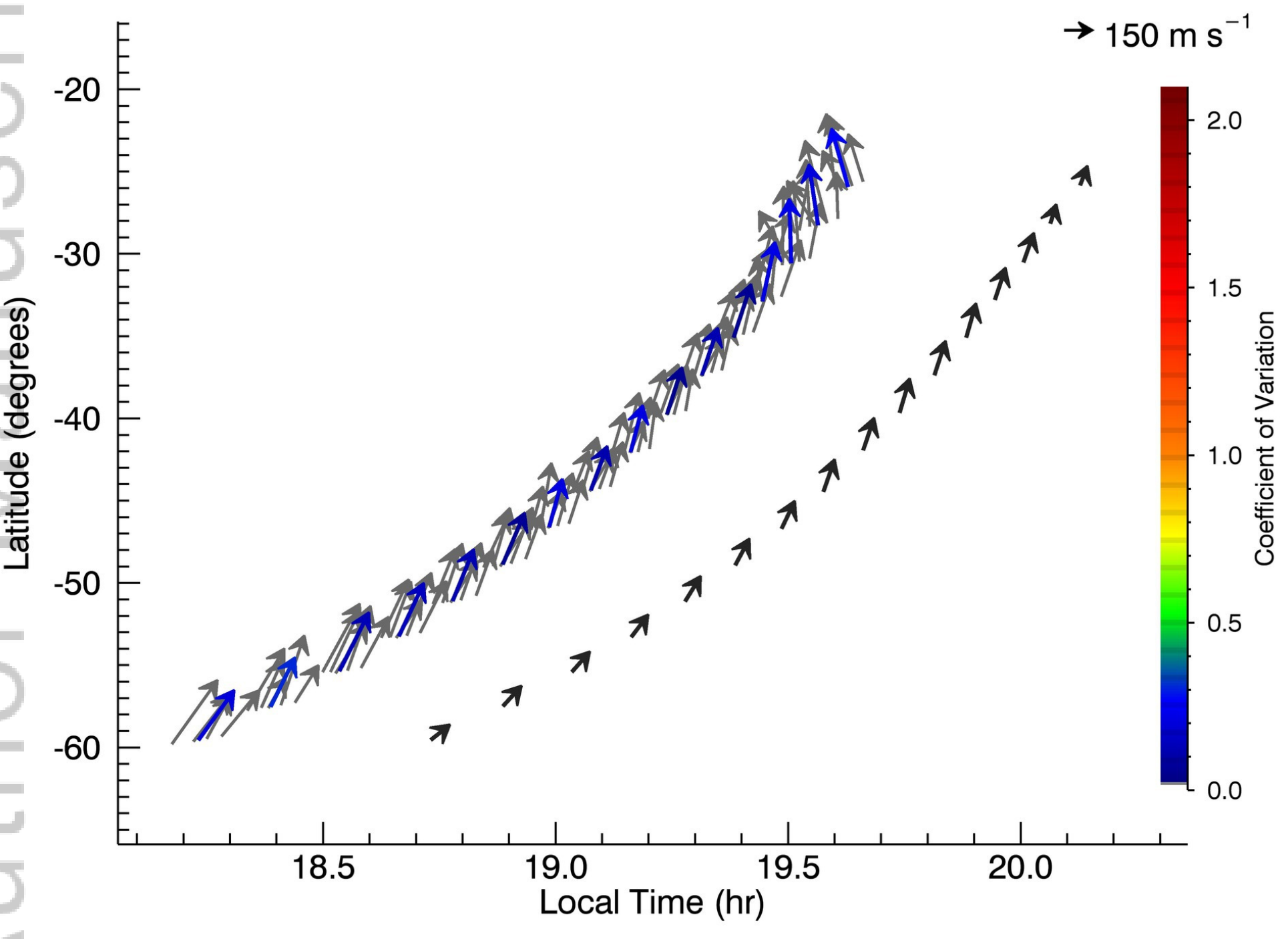

2019JE005957-f02-z-.jpg 


\section{Averaged NGIMS and M-GITM Wind Profiles}

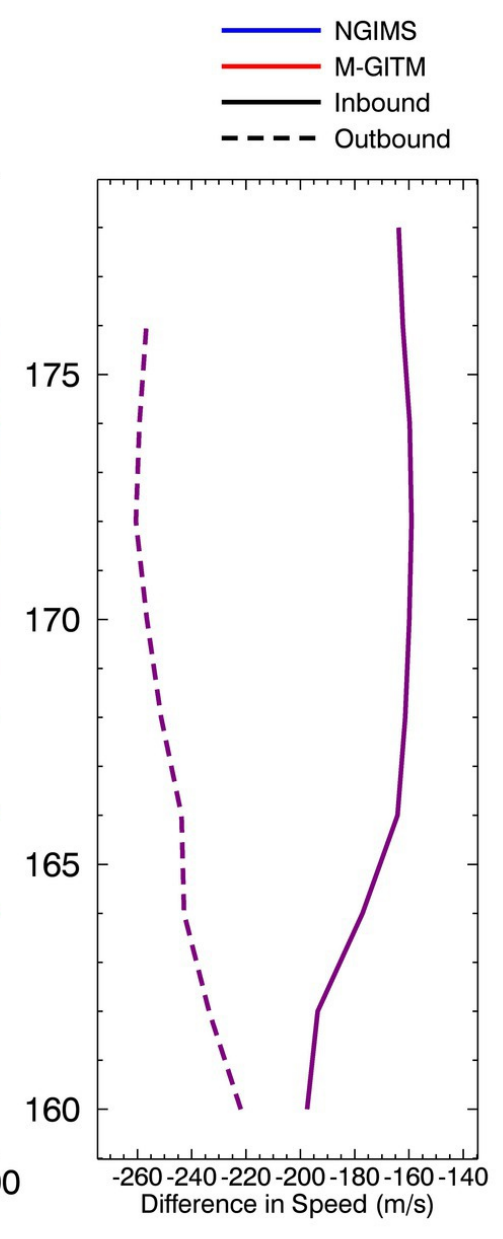

2019JE005957-f03-z-.jpg 
Wind Velocities, January 2017 Campaign

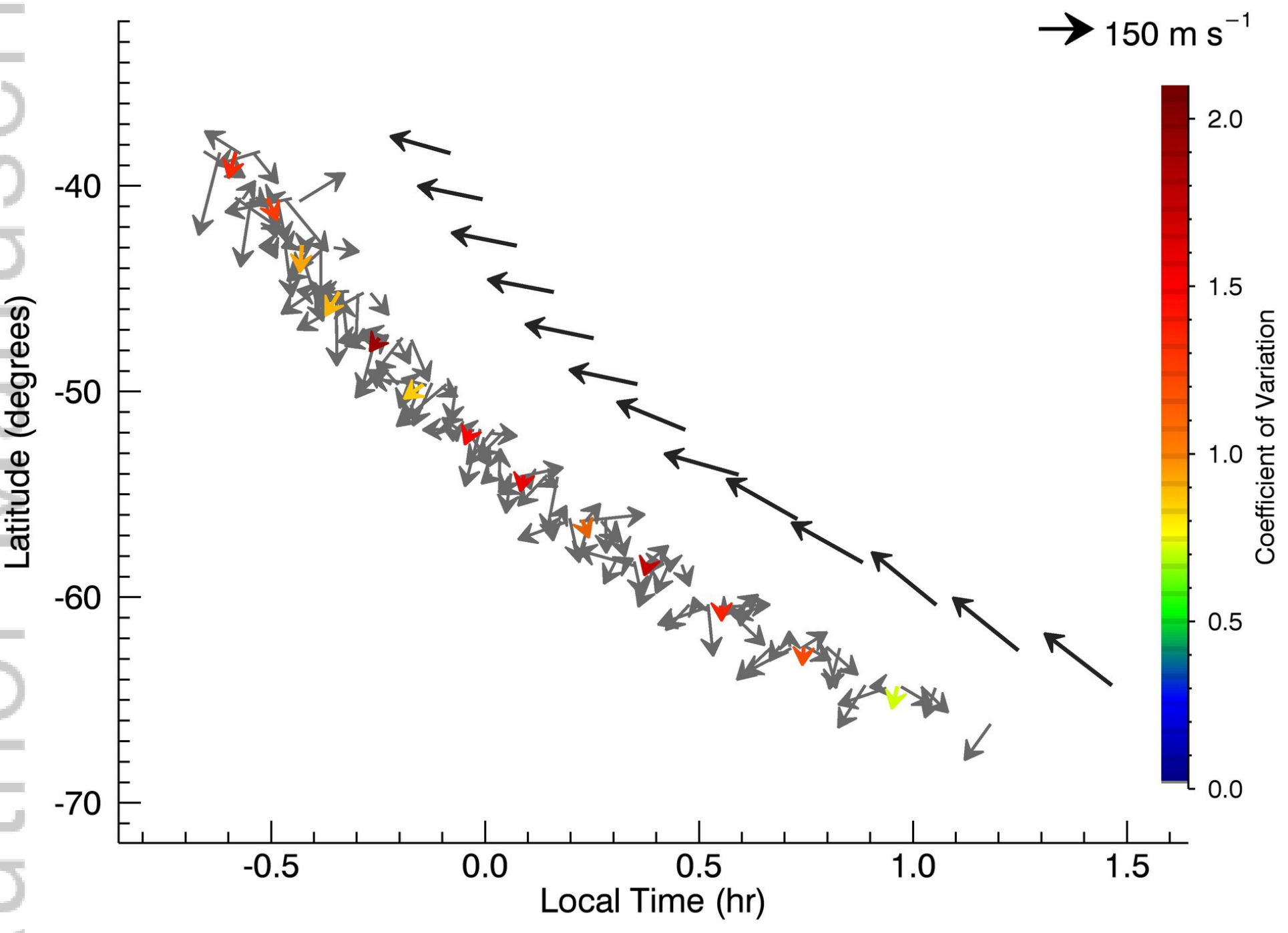

2019JE005957-f04-z-.jpg 


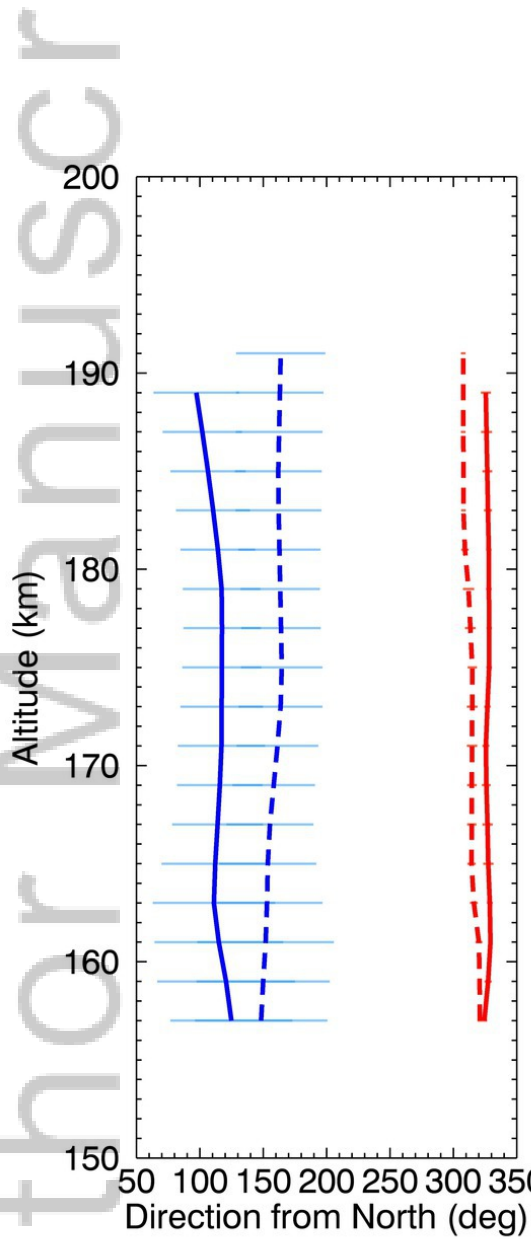

Averaged NGIMS and M-GITM Wind Profiles

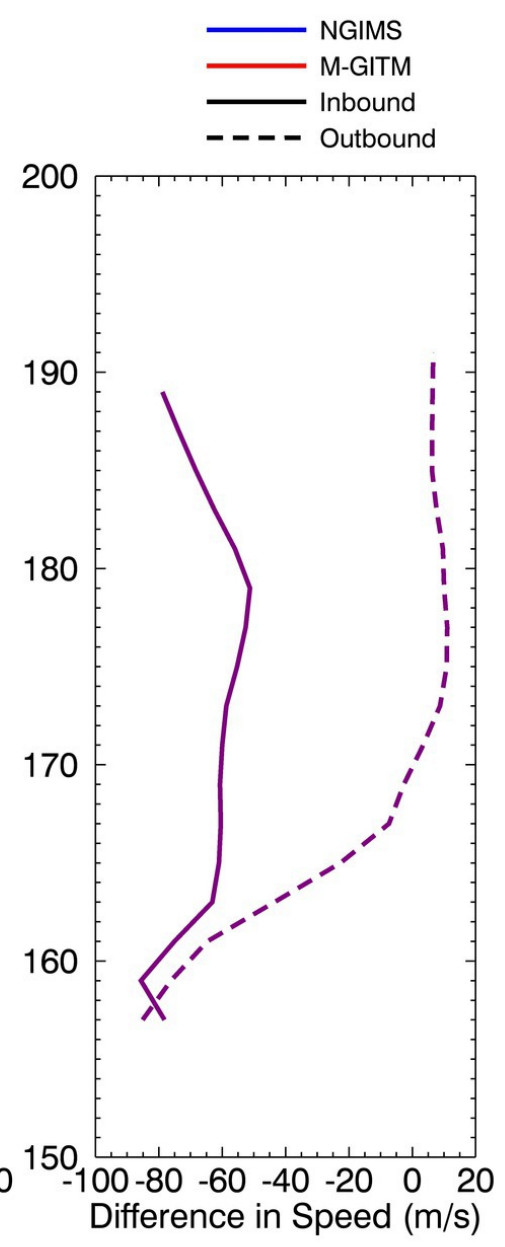

2019JE005957-f05-z-.jpg

This article is protected by copyright. All rights reserved. 
Wind Velocities, May 2017 Campaign

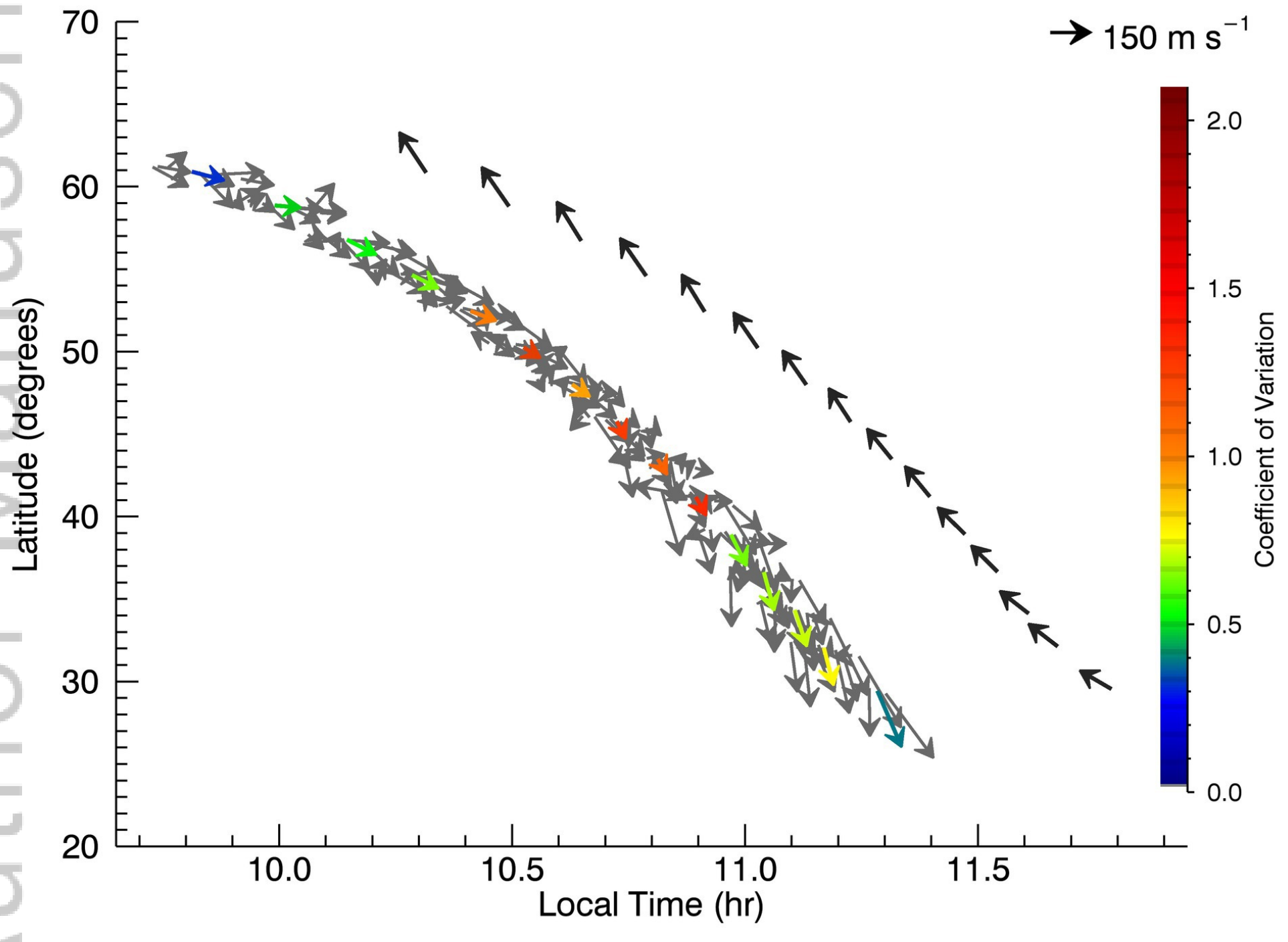

2019JE005957-f06-z-.jpg 
Averaged NGIMS and M-GITM Wind Profiles

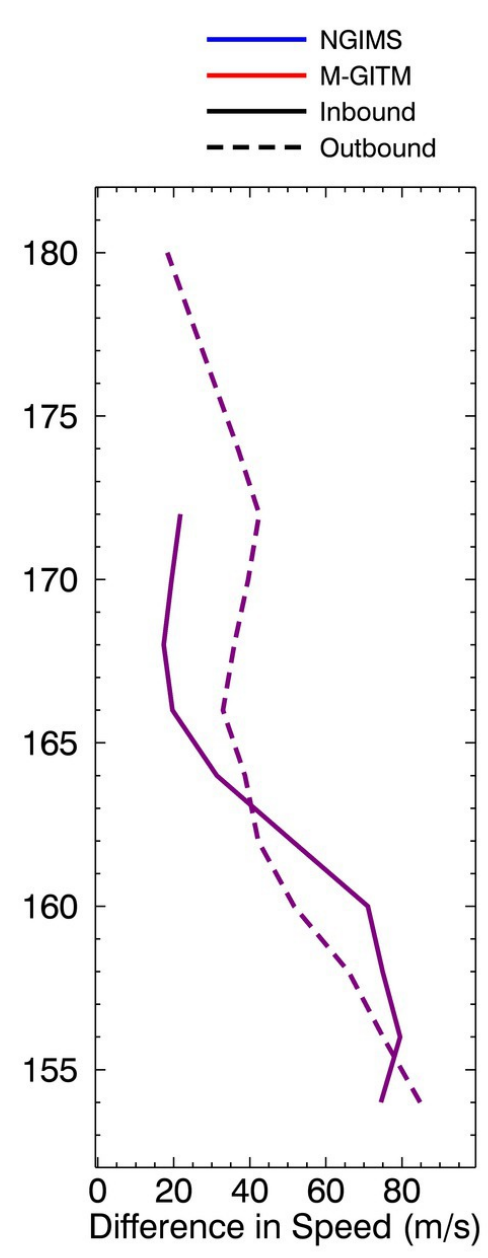

2019JE005957-f07-z-.jpg 
Wind Velocities, December 2017 Campaign

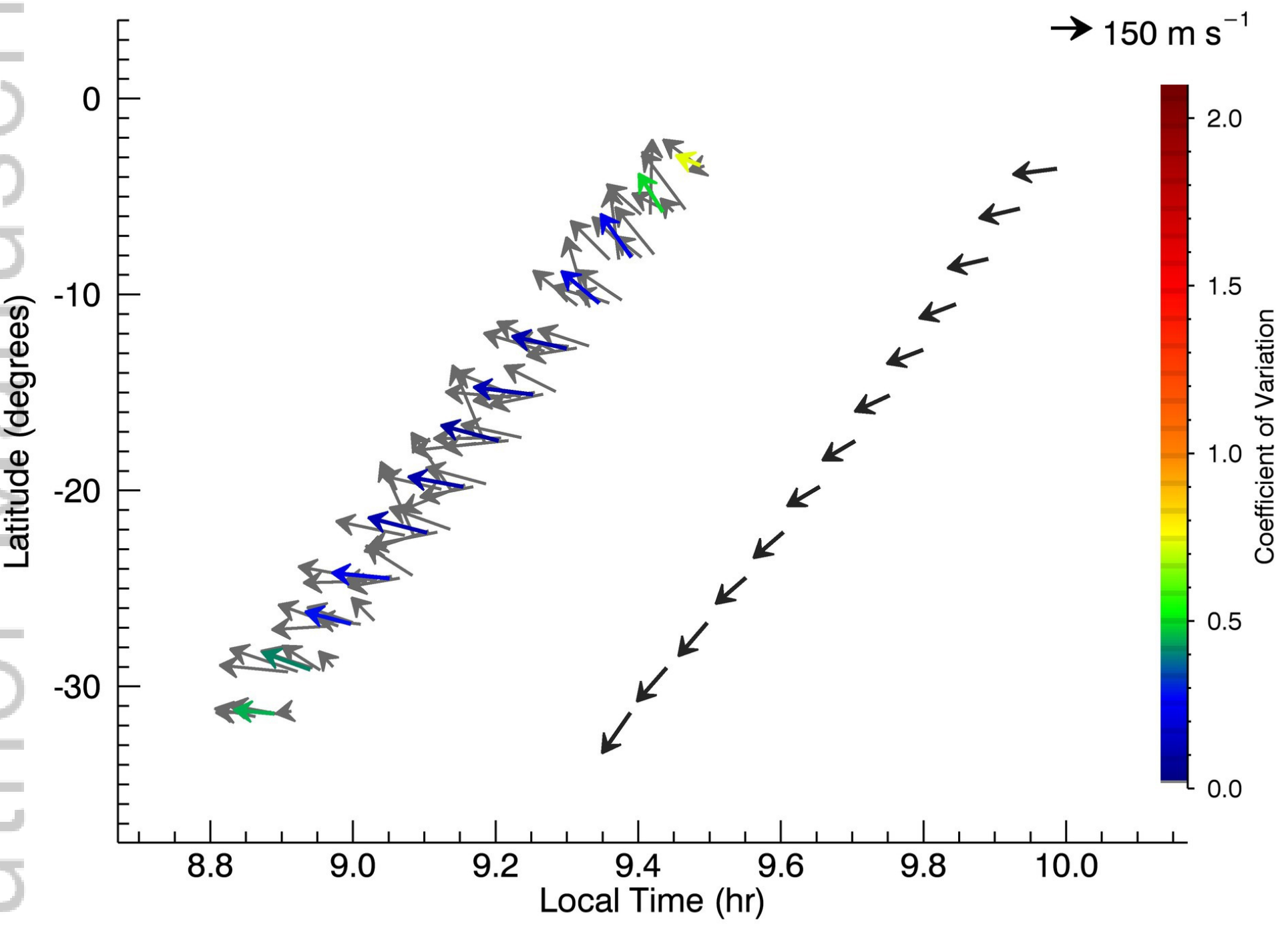

2019JE005957-f08-z-.jpg 
Averaged NGIMS and M-GITM Wind Profiles
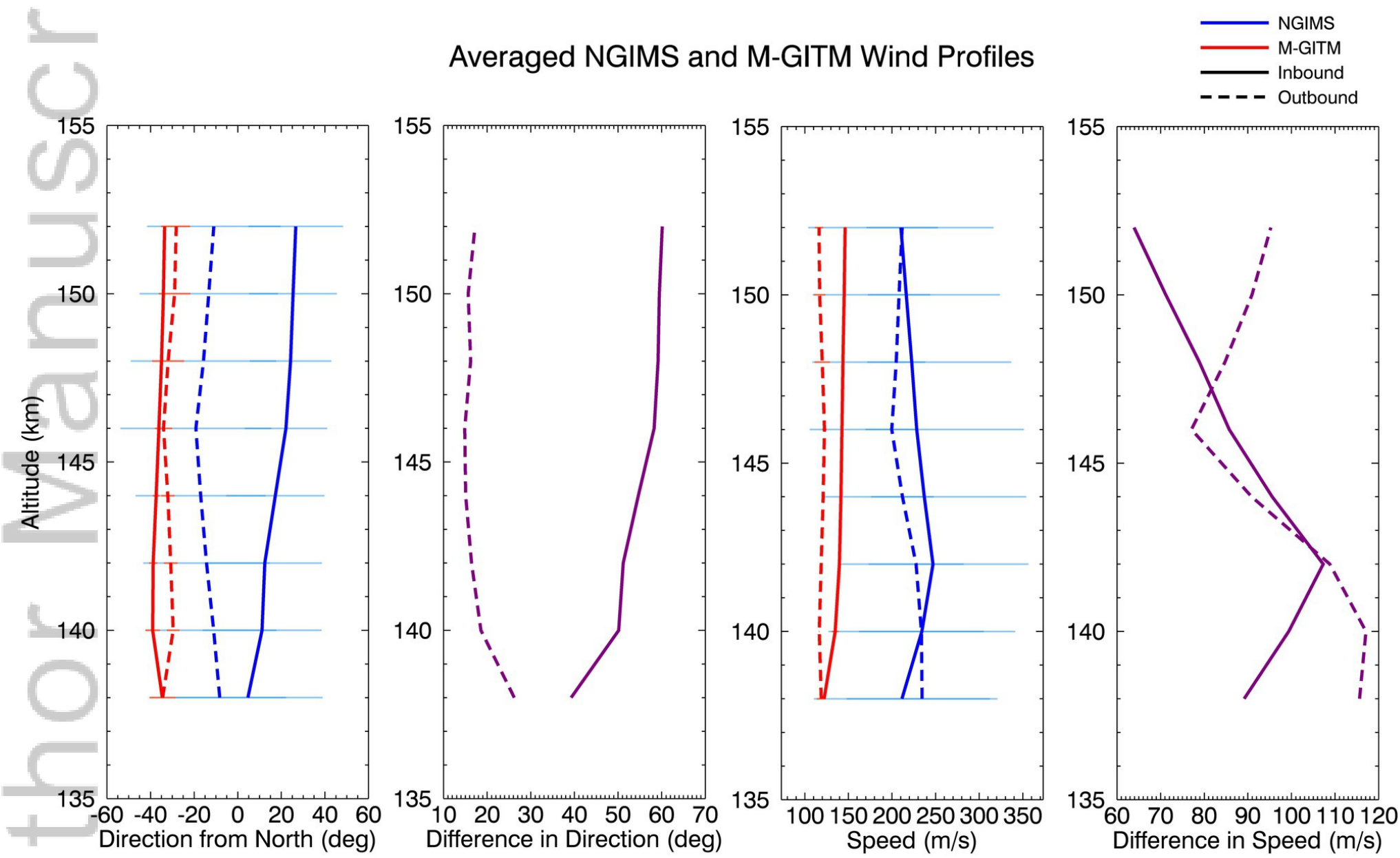

2019JE005957-f09-z-.jpg

This article is protected by copyright. All rights reserved. 
Wind Velocities, February 2018 Campaign

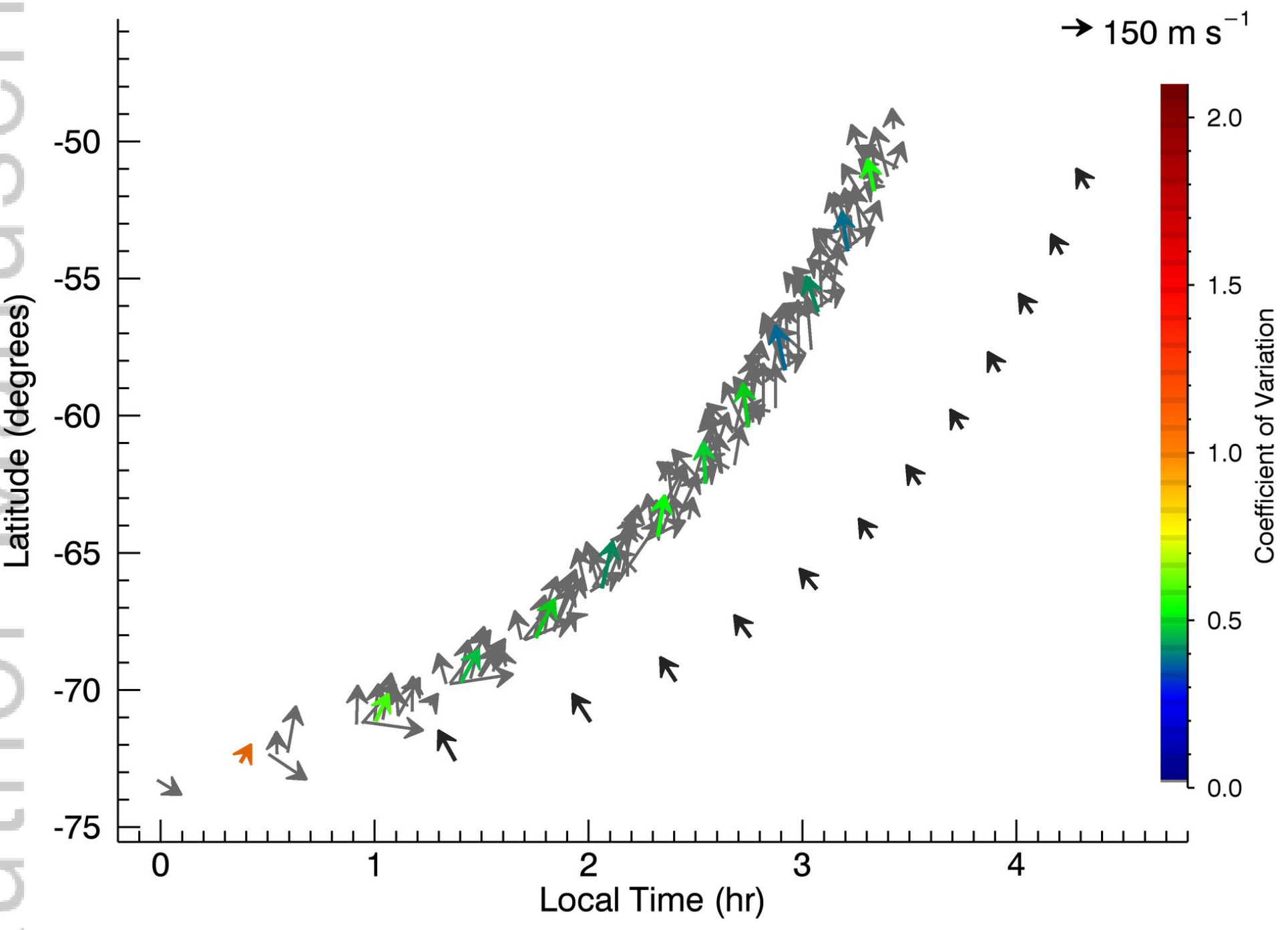

2019JE005957-f10-z-.jpg 


\section{M-GITM Simulated Temperatures and Horizontal Circulation Pattern}

$250.0 \mathrm{~m} / \mathrm{s}$

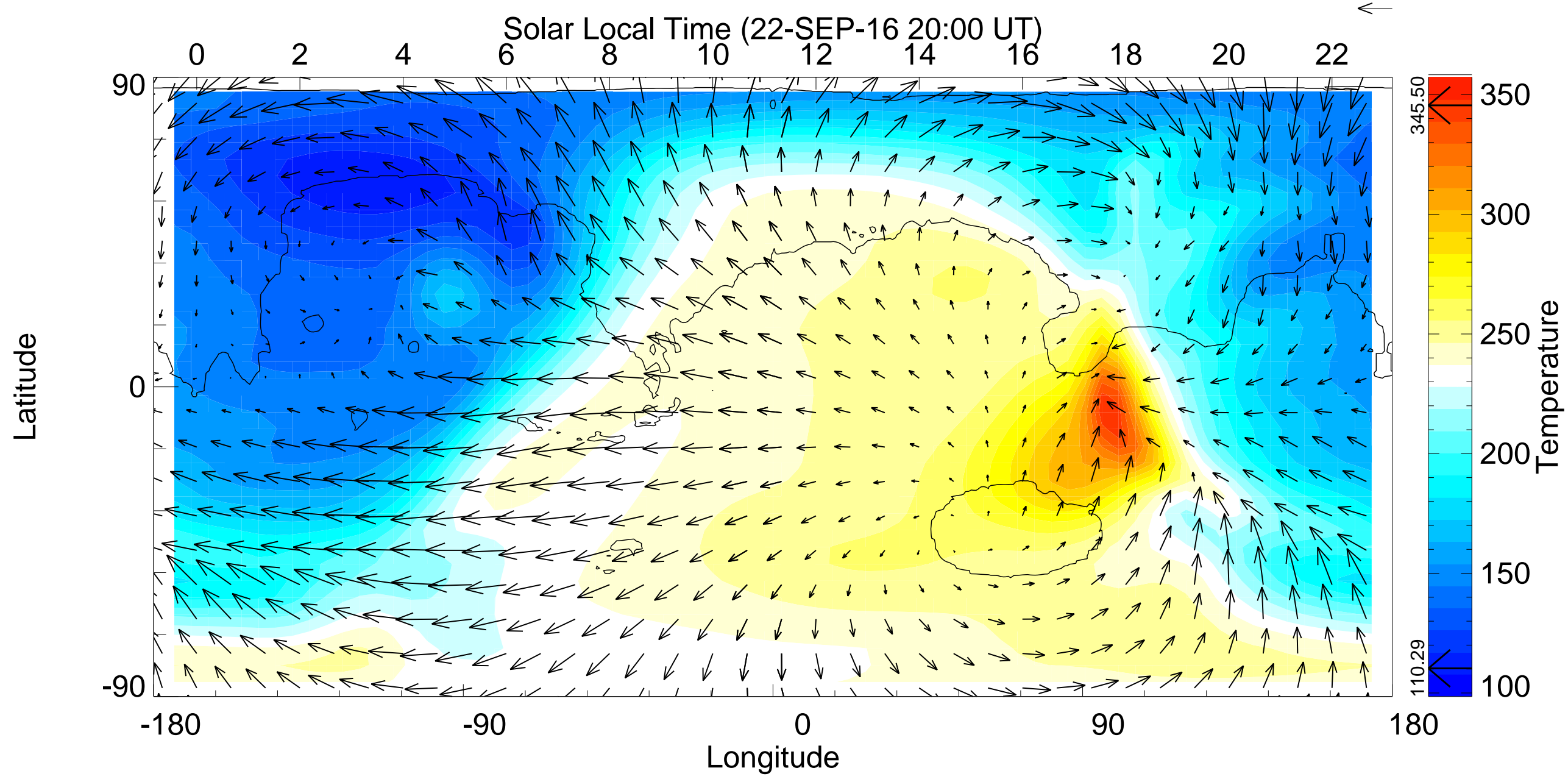

This article is protected by copyright. All rights reserved. 


\section{M-GITM Simulated Temperatures and Horizontal Circulation Pattern}

$250.0 \mathrm{~m} / \mathrm{s}$

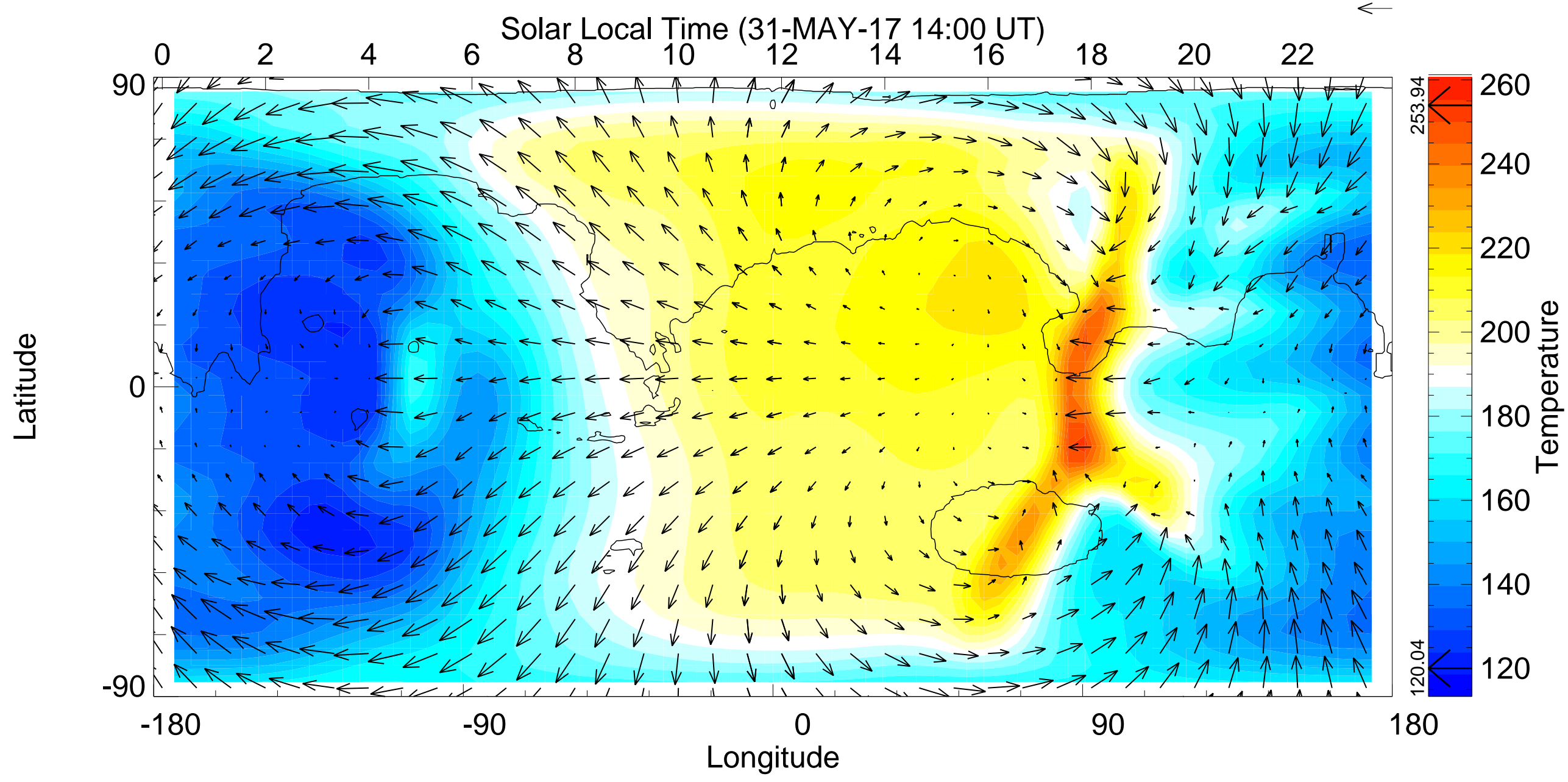

This article is protected by copyright. All rights reserved. 


\section{M-GITM Simulated Temperatures and Horizontal Circulation Pattern}

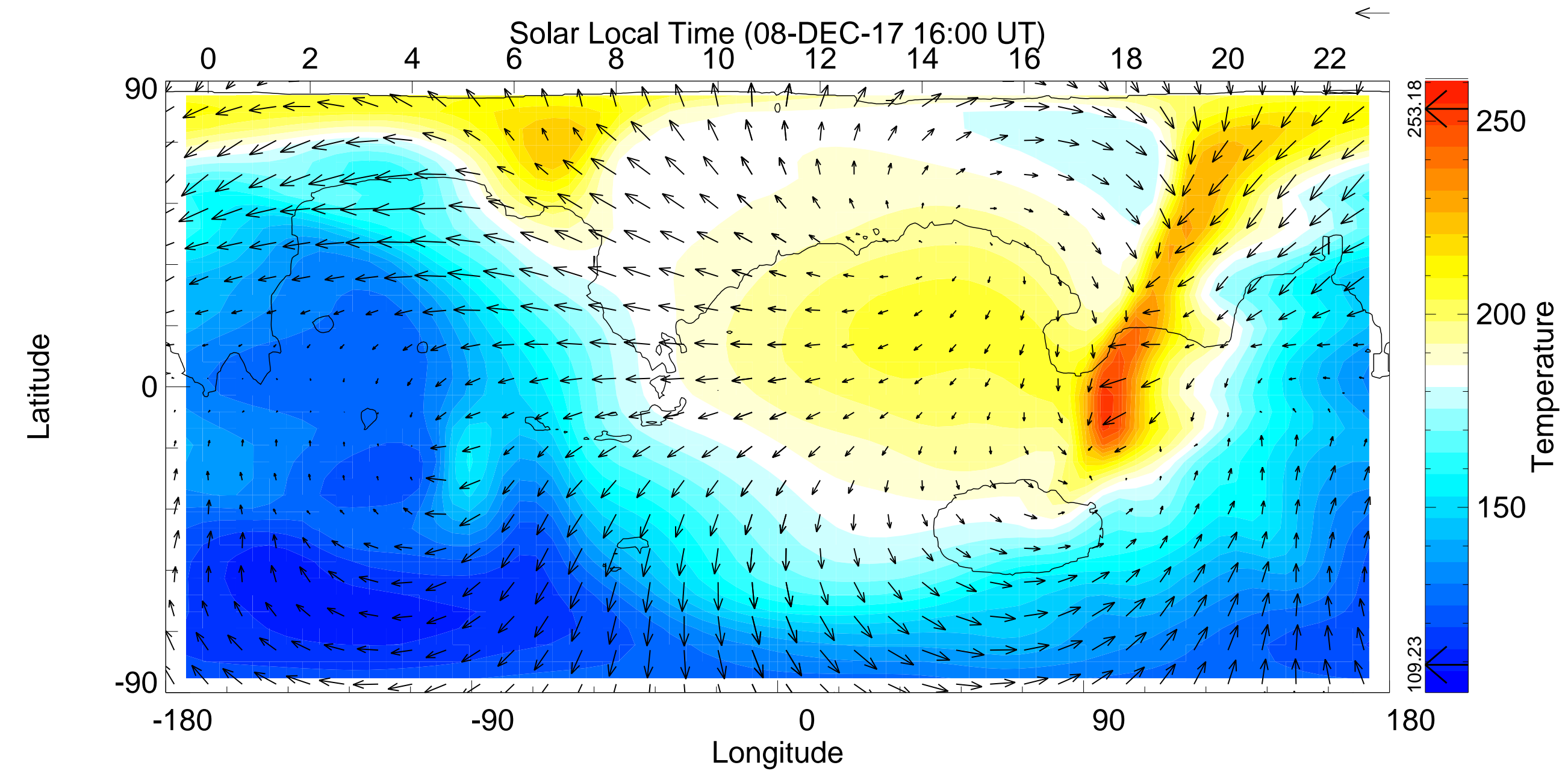

This article is protected by copyright. All rights reserved. 